\title{
Traduire le terme oppidum : un exemple des difficultés posées par le Bellum ciuile de César
}

Translating the Term Oppidum: An Example of the Difficulties Arisen by Caesar's Bellum ciuile

\section{Sabine Lefebvre}

\section{OpenEdition}

\section{Journals}

Édition électronique

URL : https://journals.openedition.org/gaia/1498

DOI : 10.4000/gaia.1498

ISSN : 2275-4776

Éditeur

UGA Éditions/Université Grenoble Alpes

Édition imprimée

ISBN : 978-2-37747-199-7

ISSN : $1287-3349$

\section{Référence électronique}

Sabine Lefebvre, «Traduire le terme oppidum : un exemple des difficultés posées par le Bellum ciuile de César », Gaia [En ligne], 22-23 | 2020, mis en ligne le 30 juin 2020, consulté le 09 décembre 2021 URL : http://journals.openedition.org/gaia/1498 ; DOI : https://doi.org/10.4000/gaia.1498

Ce document a été généré automatiquement le 9 décembre 2021.

Gaia. Revue interdisciplinaire sur la Grèce archaïque 


\title{
Traduire le terme oppidum : un exemple des difficultés posées par le Bellum ciuile de César
}

\author{
Translating the Term Oppidum: An Example of the Difficulties Arisen by
} Caesar's Bellum ciuile

\author{
Sabine Lefebvre
}

\section{NOTE DE L'AUTEUR}

Tous mes remerciements vont à Isabelle Cogitore et Marianne Coudry pour leur relecture attentive ainsi qu'à Jean-Pierre De Giorgio et Stéphanie Wyler qui ont largement participé au débat ayant donné naissance à ce travail. Afin d'alléger les notes de bas de page, toutes les références au Bellum ciuile de César sont mentionnées sous la forme $B C$.

\section{Introduction}

1 Dans le cadre de la nouvelle traduction des deux œuvres de César pour les Belles Lettres $^{1}$, nous avons réfléchi aux problèmes posés par la traduction d'un texte qui a déjà été très souvent traduit, pour des destinations très variées. De la traduction de la Collection des Universités de France (CUF) ${ }^{2}$, à visée universitaire essentiellement, où le français est mis en parallèle avec le latin, à la traduction destinée à des manuels scolaires, on constate des divergences dans le style et la formulation.

2 Notre publication ne comprend pas le texte latin. Aussi, nous avons fait le choix d'une traduction dynamique, plus contemporaine dans l'usage du vocabulaire, permettant une lecture suivie aussi par des non spécialistes, mettant en valeur le visuel des scènes de bataille ou l'oralité des discours des différents protagonistes par exemple. C'est la 
langue cible, celle du lecteur que nous avons privilégiée ${ }^{3}$. Le choix a donc été fait de tout traduire, de ne pas laisser de termes latins dans le texte produit ${ }^{4}$. Cela nous a conduit à réfléchir au choix des mots français qui devaient alors être utilisés; le problème s'est particulièrement posé pour oppidum.

3 Je me propose de présenter le résultat de notre réflexion, plus particulièrement dans le cadre du Bellum ciuile. Dans un premier temps, je ferai quelques rappels sur le terme oppidum $^{5}$. Puis j'évoquerai l'emploi par César de ce terme, avant de terminer par les choix de traduction du mot, en fonction du contexte de publication, cela pour quelques dossiers.

\section{Définition du terme oppidum}

Le terme a suscité et suscite encore de très nombreux travaux : lié au concept urbain ${ }^{6}$ et au développement d'entités à vocation urbaine, il est difficile à cerner ${ }^{7}$. La première approche consiste à tout simplement regarder la définition du Dictionnaire Gaffiot ${ }^{8}$ - «ville fortifiée, place forte, tout endroit fortifié »- ou du Dictionnaire Lewis et Short ${ }^{9}-$ «1. A town (of towns other than Rome, which was called Urbs; though occasionally the term oppidum was applied to Rome); 2. A fortified wood or forest, among the Britons; 3. The barriers of the circus ». Il apparait clairement que le mot oppidum est utilisé lorsque qu'il y a "un regroupement humain [...] conséquence de la formation d'une communauté ${ }^{10}$ " définie par une limite sacrée ${ }^{11}$. Le terme apparaît pour la première fois, chez les auteurs latins ${ }^{12}$, chez Cicéron ${ }^{13}$, puis chez César, chez Varron ${ }^{14}$, et chez Tite-Live ${ }^{15}$ qui désigne ainsi l'enceinte de Rome, mais qui l'utilise aussi pour désigner des structures de la Gaule cisalpine celtisée ${ }^{16}$, pas forcément fortifiées ${ }^{17}$. Plus tard, on retrouve le mot chez Pline l'Ancien, accompagné de précisions - oppidum ciuium Romanorum, oppidum Latinum - et cela pour des régions autres que la péninsule italienne ou la Gaule ${ }^{18}$. Mais aucun auteur antique ne nous fournit une définition précise de ce terme et d'ailleurs la réalité recouverte par ce terme peut l'être aussi par d'autres mots : Clastidium $^{19}$, ville ligure, est qualifiée par Polybe de polis ${ }^{20}$, c'est-à-dire de cité, et de uicus ${ }^{21}$ et d'oppidum ${ }^{22}$ par Tite-Live! Certes, César, dans le Bellum Gallicum, utilise le terme oppidum pour une structure bretonne désignée ainsi par les autochtones semble-t-il, dont il fournit une courte description ${ }^{23}$. Il fournit aussi des descriptions de sites d'oppida gaulois, comme Alésia ${ }^{24}$ ou Vesontio (Besançon) ${ }^{25}$, mais cela ne constitue pas une définition du terme.

5 Comme le rappelle Stephan Fichtl, «ce terme doit être pris comme celui qui s'approchait le plus d'une réalité non méditerranéenne, que César découvrait au fur et à mesure qu'il s'enfonçait sur le sol gaulois ${ }^{26} »$. Réalité qui néanmoins devait être connue des négociants romains depuis l'établissement de relations économiques entre Rome et les peuples gaulois. Mais cette réalité est multiple et « César emploie, en fait, le terme d'oppidum pour des réalités très différentes les unes des autres ${ }^{27}$ ». C'est par glissement qu'oppidum en est arrivé à désigner le chef-lieu d'un territoire, la ville d'un pays, d'un État, d'une organisation politique, d'une cité, déjà chez Cicéron ${ }^{28}$.

Bien plus tard, les archéologues s'en sont emparés pour désigner un élément bien précis du territoire des peuples préromains de Gaule, plus spécifiquement celtiques ; en témoigne un dossier dans lequel Christian Goudineau proposait au grand public une typologie des oppida ${ }^{29}$. L'oppidum le plus important, le mieux protégé a souvent été désigné comme « capitale ", sans que l'on puisse imaginer une véritable centralisation 
de l'espace tribal autour de ce pôle. La formule " civilisation des oppida ", notion définie par Joseph Déchelette, est ainsi liée aux découvertes menées depuis un siècle et demi ${ }^{30}$.

7 Ces caractéristiques, telles que les archéologues les ont définies, sont les suivantes ${ }^{31}$ :

- des défenses naturelles : son accès est souvent rendu difficile soit par des pentes raides, soit par un isolement hydrographique; l'enceinte n'est donc pas une obligation, César mentionnant un oppidum ouvert, Geneua ${ }^{32}$, tout comme Tite-Live qui évoque pour l'année 217 av. J.-C. l'évacuation des oppida non fortifiés ${ }^{33}$. Néanmoins, les oppida apparaissent souvent comme étant fortifiés ${ }^{34}$;

- l'oppidum est habité de façon permanente, avec des activités économiques, politiques et parfois religieuses. L'aspect économique est largement valorisé par César, en particulier dans les sept livres du Bellum Gallicum qu'il a écrit : c'est ce qu'il évoque en premier pour les oppida qu'il mentionne, car il y ravitaille souvent ses troupes. Quant à l'aspect politique, César ne l'oublie pas, signalant que les décisions importantes des divers peuples se prennent dans le cadre des oppida. Il mentionne, pour certains, une physionomie déjà urbaine, comme Auaricum (Bourges) qui est même qualifiée d'urbs ${ }^{35}$.

Chez les archéologues ${ }^{36}$, deux écoles s'opposent dans la définition d'oppidum. En 2000, Venceslas Kruta propose une définition très large: il s'agit pour lui de tout lieu d'habitat - «les grandes agglomérations ", mais pas seulement - fortifié de l'âge du fer en Europe occidentale, en prenant en compte le rôle centralisateur des activités, entre autres économiques avec la présence permanente d'artisans et l'insertion dans un réseau commercial, mais aussi religieuses et administratives ${ }^{37}$.

Stephan Fichtl, dans deux ouvrages sur les oppida datés de $2000^{38}$ et de $2004^{39}$, préfère quant à lui une définition plus stricte ${ }^{40}$, prenant en compte la taille de ceux-ci (plus de 15 ha, les plus petits étant des castella; Wolfgang Dehn ${ }^{41}$ propose lui 30 ha minimum ; Jean-Paul Guillaumet ${ }^{42}, 50 \mathrm{ha}$ ) construits au II $^{\mathrm{e}}$ siècle av. J.-C. et sur une zone allant de l'arc alpin au sud de la Grande-Bretagne. Il évoque d'ailleurs l'utilisation du terme oppidum chez César, mais avant tout dans le Bellum Gallicum ${ }^{43}$, sans vraiment tenir compte du Bellum ciuile, dont une grande partie de l'action se situe en Illyrie, Macédoine et péninsule Ibérique, c'est-à-dire en dehors du cadre géographique de la « civilisation des oppida ${ }^{44} »$.

Les auteurs anciens semblent opposer oppidum à urbs qui est une ville ouverte, mais qui, au fil du temps, a pu être entourée d'une enceinte, sans que le terme la désignant change ; mais l'opposition n'est pas si évidente ${ }^{45}$. Cela pose donc le problème de savoir si on peut assimiler oppidum à "ville ", ce que fait Stephan Fichtl dans le titre d'un de ses ouvrages ${ }^{46}$, et on verra que nous avons fait le choix dans notre traduction de recourir très fréquemment à cette assimilation, que l'on retrouve par exemple chez Aulu-Gelle ${ }^{47}$. Il convient bien entendu d'être plus prudent avec le terme "cité », qui traduit souvent ciuitas $^{48}$, c'est-à-dire une circonscription administrative considérée généralement comme étant de type romain ${ }^{49}$, comprenant un territoire et un ou plusieurs centres urbains, qui peuvent être des oppida ${ }^{50}$.

11 En résumé, l'oppidum serait un site de hauteur, fortifié par la nature ou par l'homme, avec des fonctions économiques et politiques essentiellement. Sauf à de rares exceptions, il n'est pas encore une urbs du point de vue romain. C'est un terme romain qui désigne une réalité celtique ${ }^{51}$, différente de ce que les Romains connaissaient.

12 Cette définition assez large est très bien applicable aux sites de Gaule celtique évoqués par César dans le Bellum Gallicum. Mais le terme a-t-il le même sens dans le Bellum 
ciuile ? Doit-on donc le traduire de la même façon ? Bibracte, oppidum des Éduens, est-il comparable à Utique, capitale de l'Afrique, également désignée par le terme d'oppidum ? Faut-il, dans les deux cas, traduire oppidum de la même façon? Ainsi que je l'ai signalé, Stephan Fichtl rappelle que «César emploie, en fait, le terme d'oppidum pour des réalités très différentes les unes des autres ${ }^{52}$ ». Cela apparaît assez nettement dans le Bellum ciuile.

\section{César et le terme oppidum dans le Bellum ciuile}

Le Bellum ciuile est postérieur au Bellum Gallicum : lors de son écriture, César a déjà utilisé le terme oppidum pour désigner un certain nombre de lieux en Gaule et en Bretagne, territoires qu'il tentait de conquérir. Dans le Bellum ciuile, il parcourt, avec ses troupes, ses alliés et ses ennemis, des régions entrées depuis plusieurs décennies dans l'Empire romain, des espaces où le cadre administratif romain et la terminologie romaine étaient connus, des territoires où la civilisation poliade était ancienne, en particulier pour la partie orientale de son champ d'action. L'utilisation du terme oppidum dans un tel contexte est donc surprenante ${ }^{53}$, ce qui n'était pas le cas dans le Bellum Gallicum, le terme oppidum employé par César l'étant alors dans le contexte pour lequel il a été défini, c'est-à-dire une Gaule celtisée peu à peu par les migrations. Que recouvre alors, pour César, le terme d'oppidum dans ces zones géographiques méditerranéennes ${ }^{54}$, la côte dalmate, la péninsule Ibérique, l'Afrique, pour lesquelles César évoque la présence d'oppida, bien différents des structures celtiques?

César va, depuis le franchissement du Rubicon en janvier 49 av. J.-C. et jusqu'en 48 à la mort de Pompée en Égypte et à sa propre arrivée à Alexandrie, raconter les diverses phases du conflit sur plusieurs champs de bataille, en Italie, à Marseille, en péninsule Ibérique puis en Grèce, et enfin à Alexandrie.

Dans le cadre du déplacement des troupes dans ces divers espaces, il est conduit à décrire et à mentionner des villes, places fortes, camps, etc., pour lesquels il utilise des termes latins comme castellum, castrum, principia, mais aussi fréquemment, oppidum. Or, la réalité des sites ainsi mentionnés ne correspond pas forcément à la définition mise au point et utilisée par les archéologues pour le monde celtique ${ }^{55}$. César ne dispose sans doute pas d'un lexique élargi pour désigner les structures plus ou moins urbaines, mais surtout plus ou moins défendues et protégées qu'il évoque, même si la variété des mots possibles est grande pour désigner le phénomène urbain ${ }^{56}$, ce qui n'est pas sa principale préoccupation. Son souci n'est pas non plus de s'approcher au plus près de la réalité institutionnelle, politique ou économique de ces sites ${ }^{57}$ - son propos n'est pas ethnographique, il est militaire - : il est beaucoup plus précis lorsqu'il évoque les camps, fortins ou campements qui, eux, jouent un rôle dans le cadre du conflit l'opposant à Pompée. La terminologie employée reflète la hiérarchie et la taille de ces structures militaires.

Or, c'est en partie sur les textes littéraires que l'on s'est fondé pour déterminer le statut ou la physionomie de ces sites, avant que les découvertes archéologiques ne permettent de nuancer et, par conséquent, de complexifier le terme oppidum. La compréhension de son utilisation par César est donc importante.

17 Afin de pouvoir être le plus précis possible dans l'analyse du terme, il convient d'en faire le recensement, soit près de 110 attestations d'oppidum ou d'oppidani - les habitants d'un oppidum -, concernant près de 30 sites. Il faut noter que le terme est 
parfois employé de façon générale et ne peut être rattaché à une ville en particulier ${ }^{58}$. L'inventaire conduit à quelques remarques générales, mon propos n'étant pas ici de faire une analyse exhaustive de l'ensemble des attestations.

Le terme oppidum utilisé par César peut souvent être mis en relation avec des fortifications, ou des opérations militaires; c'est la puissance du site qui est ainsi évoquée ${ }^{59}$. Ainsi pour Iguuium ${ }^{60}$, le verbe munire lié à oppidum signale les fortifications mises en place par l'ancien préteur Thermus, ce qui signifie que la ville n'était guère fortifiée avant cela. Mais lorsque César évoque le sentiment des habitants, qui a pu s'exprimer lors d'une réunion du corps civique, c'est le terme municipium qu'il emploie ${ }^{61}$, évoquant le statut juridique de la communauté, respectant en cela la terminologie juridique.

même Auximum ${ }^{62}$, mentionné comme oppidum ${ }^{63}$ tenu par Attius avec quelques cohortes, possède, depuis l'installation des Romains dans le Picenum ${ }^{64}$, de forts murs d'enceinte faite de pierres rectangulaires, en opus quadratum de tuf local ${ }^{65}$; ils atteignent $10 \mathrm{~m}$ de haut. Cette colonie, depuis 157 av. J.-C. selon Velleius Paterculus ${ }^{66}$, est de plus sise sur une colline de près de $450 \mathrm{~m}$ de haut, entourée du mur d'enceinte : la surface protégée n'est que de 16 ha. Sa physionomie correspond à ce que l'on a pu retenir de la définition des oppida celtiques. De fait, c'est en tant que place forte que le site est évoqué par le terme oppidum, en lien avec l'importance de l'enceinte ${ }^{67}$. Ces murs abritent une garnison ${ }^{68}$, c'est bien l'aspect militaire qui est ici mis en avant. Il en est de même à Lissus, où César a chargé le conuentus des citoyens romains d'améliorer les fortifications ${ }^{69}$.

On peut évoquer un autre exemple pris dans le livre III, celui de Salone ${ }^{70}$. Cette ville, située dans la future province de Dalmatie dont elle devient la capitale à l'époque césarienne, est un port à l'embouchure du Jadro. César fournit des informations sur ce site qu'il qualifie d'oppidum dans le cadre du siège qu'il mène. Nous sommes bien là dans un contexte militaire. L'auteur précise ensuite la topographie: Salone est défendue par sa position naturelle, une colline. Nous nous rapprochons ici des descriptions faites dans le Bellum Gallicum, par exemple celle concernant Vesontio ${ }^{71}$.

21 Le terme oppidum est aussi souvent associé à la présence de garnisons : c'est le cas à Asculum $^{72}$, à Auximum ${ }^{73}$, et à Corfinium ${ }^{74}$, mais aussi à Sulmo ${ }^{75}$, où se trouve une garnison commandée par Q. Lucretius et Attius Pelignus ${ }^{76}$, ou encore à Hadrumète ${ }^{77}$. C'est bien l'action des citoyens romains fermant les portes de Corduba et garnissant les murs d'hommes pour se protéger de Varron qui justifie l'emploi d'oppidum pour désigner la capitale de la province d'Ultérieure ${ }^{78}$, qui est bien alors une "ville», traduction privilégiée par le Groupe César, tout en étant une "place» rendue forte par cette action, traduction retenue par Pierre Fabre dans la CUF. C'est parce que Pompée place des troupes dans les villes de la côte qu'elles sont désignées par César comme des oppida ${ }^{79}$, dont Dyrrachium ${ }^{80}$.

Mais un oppidum n'étant pas un camp, castra, César distingue bien les deux : à Corfinium, il installe son camp - castra ${ }^{81}$ - sous les murs de l'oppidum, tout comme Octavius à Salone $^{82}$. Pour lui la distinction entre les deux est bien claire. La mention d'oppidum n'est jamais très loin de la mention d'un camp, castra; les deux entités n'ont pas le même rôle et n'abritent pas la même population. S'il peut y avoir des troupes dans un oppidum, il y a aussi des habitants qu'il n'y a pas dans un camp. Ainsi oppidani désigne les habitants par opposition aux soldats, comme on le voit à Sulmo ${ }^{83}$ - Pierre Fabre traduit d'ailleurs oppidani et milites par " civils et soldats »-, ou à Oricum ${ }^{84}$. Lors d'un 
siège, les oppidani, ceux qui se trouvent à l'intérieur de la ville, sont alors des assiégés, comme à Massalia ${ }^{85}$. On peut mentionner le cas d'Octogesa, située sur l'Èbre, et mentionnée par César ${ }^{86}$. Malheureusement ce site des Ilergètes n'a pas été clairement identifié et donc localisé. Il est donc difficile de dire ce qui conduit César à employer ce terme, sans connaître le cadre topographique en particulier.

Plus loin, dans le livre III, on peut faire la même constatation: ainsi, lorsque César évoque les quartiers d'hiver que prend Pompée, il mentionne un certain nombre de villes et les oppida maritima, qui sont les autres villes de la côte ${ }^{87}$. Cette localisation des quartiers d'hiver a pour but de surveiller et de contrôler les ports afin d'éviter un débarquement de César, resté en Italie. Un élément est ici à prendre aussi en compte dans le choix de l'emploi d'oppidum: Pompée, afin de préparer cet hiver, a rassemblé dans ces diverses villes de grandes quantités de blé. J’ai rappelé que, pour César, dans le Bellum Gallicum, l'oppidum était souvent le lieu où il trouvait des ressources pour ses troupes. Cette dimension est donc reprise ici. Les oppida maritima servent d'entrepôts à Pompée pour le blé venu de Thessalie, de Crète, d'Égypte.

Il est là encore étonnant que César n'emploie pas les termes désignant le statut de ces cités : Asculum Picenum, conquise en 268 av. J.-C., est devenue alors une ciuitas foederata, puis, après la guerre des Socii en $89^{88}$, un municipium. Dans un contexte militaire, ce n'est pas le statut des cités qui l'intéresse mais leur potentiel militaire: Asculum Picenum est bien défendu par un site composé d'une terrasse rocheuse bordée par trois pentes. Elle a surtout une garnison conséquente ${ }^{89}$, que Lentulus Spinther tente d'entraîner à sa suite lors de sa fuite ${ }^{90}$.

De façon générale, le vocabulaire associé au terme oppidum est presque toujours à consonance militaire : on parle des murs, des troupes, de sièges ${ }^{91}$, de prises par la force, de résistance, de fuite ${ }^{92}$ ou d'expulsion de ces lieux protégés ${ }^{93}$, d'entrée ou sortie de délégations $\mathrm{s}^{94}$; cela est en particulier visible lors de l'évocation de Massalia ${ }^{95}$, de Capoue $^{96}$, de Messine ${ }^{97}$ ou de Rhodes ${ }^{98}$.

Il faut noter quelques cas pour lesquels il est difficile de trouver la dimension militaire comme pour Cingulum dont la fondation est évoquée ${ }^{99}$.

L'emploi d'oppidum sous le stylet de César ne semble donc pas anodin, que cela soit dans le Bellum Gallicum et plus encore dans le Bellum ciuile. Un exemple le confirme: Carmona $^{100}$ occupe un site remarquable, en hauteur, dominant une riche plaine agricole, ce qui a sans doute justifié sa fondation par les Carthaginois. Or, trois termes sont utilisés par César pour désigner la ville ${ }^{101}$ : elle est tout d'abord une ciuitas, et la plus puissante de la province. César ne précise pas ce qui fait sa puissance, mais la suite de son texte permet de comprendre qu'il s'agit de son potentiel défensif; la traduction ici ne peut être que "cité", en parfaite adéquation avec le système administratif romain dans une province organisée en 197 av. J.-C. Le second terme est arx, que l'on peut traduire par « citadelle »; la topographie de Carmona permet d'employer ce terme pour la partie la plus élevée de la ville. Enfin, César utilise oppidum, qui désigne la ville où ont été placées les cohortes de Varron qui sont chassées par les habitants ; c'est bien ici le contexte militaire qui est rappelé, d'où l'utilisation du terme par César que nous avons traduit par «ville». Notre traduction d'oppidum doit rendre cette subtilité de l'emploi du terme et permettre ainsi au lecteur de la saisir. 


\section{Les choix de traduction}

28 J'ai privilégié quelques dossiers pour justifier les choix de traduction que nous avons faits, car il est bien entendu impossible de tout passer en revue. Pour montrer la difficulté qui réside dans le choix du bon terme, j'ai mis en parallèle, pour chacun des sites retenus, trois traductions, celle de la collection Nisard ${ }^{102}$, publiée en 1865 , celle de Pierre Fabre dans la CUF ${ }^{103}$ et celle du Groupe César. Nous avons en général choisi de traduire oppidum par « ville $»^{104}$.

29 Le premier dossier concerne Corfinium ${ }^{105}$, dont la situation stratégique explique l'importance ; elle était sans doute enceinte de murs forts, ce qui explique la résistance contre César, menée par L. Domitius Ahenobarbus.

Tableau 1. - Corfinium.

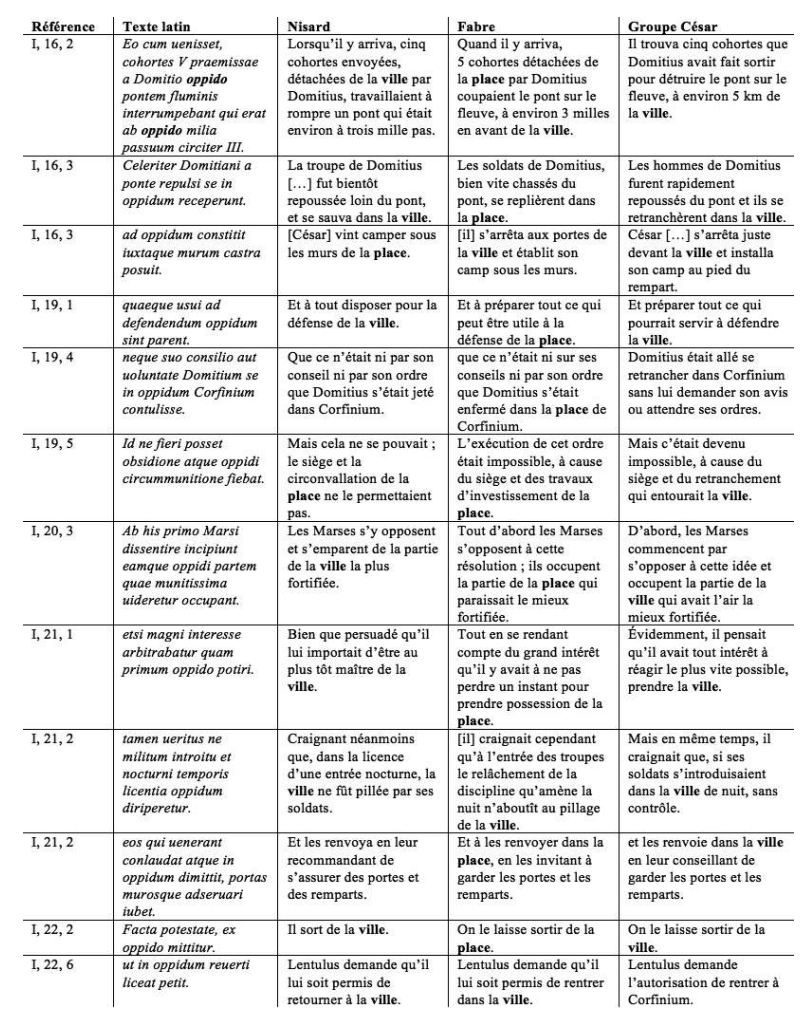

30 La dimension militaire est bien liée à l'emploi du terme oppidum, qui est en lien avec la garnison, la stratégie militaire. C'est cette dimension que Pierre Fabre a voulu le plus souvent rendre dans sa traduction; il convient de noter les rares emplois de "ville" par ce dernier, en lien non plus avec une action militaire, mais lors du pillage des biens de la communauté civile ou alors que César a octroyé sa grâce à Lentulus Spinther. Nous avons choisi de privilégier la dimension urbaine de Corfinium, en traduisant oppidum par « ville ", le contexte militaire étant rendu par les actions décrites.

31 César poursuit sa campagne en Gaule : Massalia constitue une étape-clé, et on ne peut nier son statut urbain. Polis grecque - c'est une colonie de Phocée fondée vers 600 av. J.-C. - , elle constitue un noyau très différent des oppida des peuples transalpins que les Romains ont découverts lors de la conquête entre 125 et 121 av. J.-C., comme l'Entremont des Salyens. C'est cependant ce terme qu'emploie César pour évoquer Massalia. 
Tableau 2. - Massalia.

\begin{tabular}{|c|c|c|c|c|}
\hline Référence & Texte latin & Nisard & Fabre & Groupe César \\
\hline II, 1,1 & $\begin{array}{l}\text { uineas turresque ad } \\
\text { oppidum agere instituit. }\end{array}$ & $\begin{array}{l}\text { Il dresse contre la ville les } \\
\text { mantelets et les tours. }\end{array}$ & $\begin{array}{l}\text { II entreprend de pousser } \\
\text { devant la place }[. . .] \text { des } \\
\text { baraques d'approches et } \\
\text { des tours. }\end{array}$ & $\begin{array}{l}\text { Vers la ville pour faire } \\
\text { avancer des baraques } \\
\text { d'approche et des tours. }\end{array}$ \\
\hline II $, 1,3$ & $\begin{array}{l}\text { Massilia enim fere tribus } \\
\text { ex oppidi partibus mari } \\
\text { alluitur. }\end{array}$ & $\begin{array}{l}\text { Marseille est baignée par la } \\
\text { mer presque de trois côtés. }\end{array}$ & $\begin{array}{l}\text { Marseille est, en effet, } \\
\text { baignée par la mer presque } \\
\text { de trois côtés. }\end{array}$ & $\begin{array}{l}\text { La mer encercle } \\
\text { pratiquement les trois } \\
\text { quarts de Marseille. }\end{array}$ \\
\hline II, 2,1 & $\begin{array}{l}\text { Sed tanti erant antiquitus } \\
\text { in oppido omnium rerum } \\
\text { ad bellum apparatus. }\end{array}$ & $\begin{array}{l}\text { Mais on avait depuis } \\
\text { longtemps pourvu la ville } \\
\text { 'une telle quantité de } \\
\text { munitions de guerre et de } \\
\text { machines. }\end{array}$ & $\begin{array}{l}\text { Mais il y avait depuis } \\
\text { longtemps dans la place un } \\
\text { tel approvisionnement de } \\
\text { matériel de guerre de toute } \\
\text { sorte. }\end{array}$ & $\begin{array}{l}\text { Mais les Marseillais } \\
\text { avaient stocké depuis } \\
\text { longtemps un tel arsenal } \\
\text { dans la ville. }\end{array}$ \\
\hline II $, 2,6$ & $\begin{array}{l}\text { Crebrae etiam per Albicos } \\
\text { eruptiones fiebant ex } \\
\text { oppido. }\end{array}$ & $\begin{array}{l}\text { En outre, les Albiques } \\
\text { faisaient de fréquentes } \\
\text { sorties. }\end{array}$ & $\begin{array}{l}\text { De plus, avec les Albiques, } \\
\text { les assiégés faisaient de } \\
\text { fréquentes sorties. }\end{array}$ & $\begin{array}{l}\text { En plus, les Albiques } \\
\text { multipliaient les sorties. }\end{array}$ \\
\hline II $, 2,6$ & $\begin{array}{l}\text { qui eruptionem fecerant in } \\
\text { oppidum reiciebant. }\end{array}$ & $\begin{array}{l}\text { [Ils] les rejetaient dans la } \\
\text { ville. }\end{array}$ & $\begin{array}{l}\text { Et rejetaient les assaillants } \\
\text { dans la place, non sans leur } \\
\text { avoir infligé des pertes } \\
\text { sérieuses. }\end{array}$ & $\begin{array}{l}\text { ils leur faisaient subir de } \\
\text { lourdes pertes et les } \\
\text { refoulaient à l'intérieur. }\end{array}$ \\
\hline III, 5,3 & $\begin{array}{l}\text { ut omnis iuuentus quae in } \\
\text { oppido remanserat. }\end{array}$ & $\begin{array}{l}\text { De voir dans la ville toute } \\
\text { la jeunesse qui était restée. }\end{array}$ & $\begin{array}{l}\text { On voyait tous les hommes } \\
\text { jeunes qui étaient restés } \\
\text { dans la place. }\end{array}$ & $\begin{array}{l}\text { on voyait, dans les espaces } \\
\text { publics et les postes de } \\
\text { garde, tous les jeunes qui } \\
\text { étaient restés là. }\end{array}$ \\
\hline III, 11,1 & $\begin{array}{l}\text { Quo malo perterriti subito } \\
\text { oppidani. }\end{array}$ & $\begin{array}{l}\text { Effrayés de cette } \\
\text { manoeuvre imprévue, les } \\
\text { habitants. }\end{array}$ & $\begin{array}{l}\text { Cette menace cause une } \\
\text { très vive alarme aux } \\
\text { assiégés. }\end{array}$ & $\begin{array}{l}\text { Ce coup imprévu prend de } \\
\text { court les assiégés. }\end{array}$ \\
\hline II, 13,3 & $\begin{array}{l}\text { ne per uim oppidum } \\
\text { expugnari pateretur. }\end{array}$ & $\begin{array}{l}\text { D'empêcher que la ville ne } \\
\text { fût prise. }\end{array}$ & $\begin{array}{l}\text { De ne pas laisser emporter } \\
\text { la place d'assaut. }\end{array}$ & $\begin{array}{l}\text { il ne fallait pas laisser les } \\
\text { soldats prendre la ville de } \\
\text { force. }\end{array}$ \\
\hline II, 13,4 & quin oppidum inrumperent. & $\begin{array}{l}\text { Elles voulaient entrer dans } \\
\text { la ville par force. }\end{array}$ & $\begin{array}{l}\text { On eut peine alors à les } \\
\text { empêcher de faire irruption } \\
\text { dans la ville. }\end{array}$ & $\begin{array}{l}\text { on avait du mal à les } \\
\text { empêcher de se ruer dans la } \\
\text { ville. }\end{array}$ \\
\hline II, 13,4 & $\begin{array}{l}\text { quod stetisse per } \\
\text { Trebonium quominus } \\
\text { oppido potirentur, } \\
\text { uidebatur. }\end{array}$ & $\begin{array}{l}\text { Trebonius qui seul, } \\
\text { pensaient-elles, les } \\
\text { empêchait de s'emparer de } \\
\text { Marseille. }\end{array}$ & $\begin{array}{l}\text { Car il semblait que la prise } \\
\text { de la place ne dépendît que } \\
\text { de Trebonius. }\end{array}$ & $\begin{array}{l}\text { l'impression que l'ordre de } \\
\text { ne pas s'emparer de la ville } \\
\text { venait directement de } \\
\text { Trebonius. }\end{array}$ \\
\hline III, 14,6 & $\begin{array}{l}\text { Itaque multis interfectis } \\
\text { reliquos infecta re in } \\
\text { oppidum reppulerunt. }\end{array}$ & $\begin{array}{l}\text { Ils le chassèrent dans la } \\
\text { ville sans qu'il eût rien fait. }\end{array}$ & $\begin{array}{l}\text { Aussi l'ennemi subit-il } \\
\text { beaucoup de pertes et fut-il } \\
\text { repoussé dans la place sans } \\
\text { avoir réussi dans son } \\
\text { entreprise. }\end{array}$ & $\begin{array}{l}\text { Le bilan est lourd du côté } \\
\text { des ennemis dont les } \\
\text { survivants, mis en échec, } \\
\text { furent refoulés dans la } \\
\text { ville. }\end{array}$ \\
\hline II, 22,5 & $\begin{array}{l}\text { Massilienses arma } \\
\text { tormentaque ex oppido. }\end{array}$ & $\begin{array}{l}\text { Les Marseillais }[\ldots] \text { nous } \\
\text { apportent leurs armes et } \\
\text { leurs machines. }\end{array}$ & $\begin{array}{l}\text { Les Marseillais }[\ldots] \text { nous } \\
\text { remettent les armes et les } \\
\text { machines de guerre. }\end{array}$ & $\begin{array}{l}\text { Les Marseillais }[\ldots] \\
\text { déposent les armes et } \\
\text { sortent les machines de } \\
\text { guerre hors de la ville. }\end{array}$ \\
\hline
\end{tabular}

Le terme oppidum est ici nettement associé au siège mené par les Césariens, à la mention des baraques d'approches et des tours mises en place en vue de la reddition de Massalia; un peu plus loin, c'est le matériel de guerre qui est évoqué, ainsi que les projectiles entassés par les Marseillais. Oppidum est donc clairement choisi par César pour évoquer ce cadre particulier. Si Pierre Fabre a choisi ici de traduire oppidum par " place ", nous avons à nouveau préféré le terme de "ville ", car Massalia a clairement un caractère urbain. César n'a pas à sa disposition d'autres termes aussi évocateurs des aspects militaires : peu après, c'est l'arx de Marseille, la citadelle, qui est mentionnée ${ }^{106}$. Un passage témoigne bien que les choix lexicaux de César ne sont pas anodins. Il utilise en effet deux termes pour désigner Marseille : d'une part urbs ${ }^{107}$, lorsque qu'il évoque le regard que l'on peut plonger au cœur de la ville depuis les hauteurs entourant Marseille. C'est là clairement l'aspect urbanistique ${ }^{108}$ qui est pris en compte, alors que, quelques mots plus loin, lorsqu'il évoque les potentiels défenseurs, il emploie à nouveau le terme d'oppidum. La dimension militaire est accentuée lorsque Pierre Fabre, tout comme nous, traduit oppidani par " assiégés ». Les autres mentions d'oppidum pour désigner Marseille sont elles aussi liées au contexte du siège. Il ne faut pas oublier que César est le patronus de Marseille, qu'il connaît donc très bien : le statut des cités, qui est connu par d'autres sources, et qu'il connaissait parfaitement, lui importe peu ici.

Utique, capitale de la province d'Afrique, est mentionnée principalement au livre II, alors que Curion arrive en Afrique. César la décrit comme un port qui permet de mettre des bateaux en cale sèche, proche de l'embouchure de la Bagrada, peu éloigné $(1,5 \mathrm{~km})$ d'un lieu escarpé où un camp est installé. 
Tableau 3. - Utique.

\begin{tabular}{|c|c|c|c|c|}
\hline Référene & Fexte latin & isard & Fabre & \begin{tabular}{|l} 
Groupe César \\
\end{tabular} \\
\hline $\mathrm{I}, 31,3$ & \begin{tabular}{l|} 
Hic uenientem Vticam \\
nauibus Tuberonem portu \\
atque oppido prohibet.
\end{tabular} & $\begin{array}{l}\text { Il refusa à Tubéron qui } \\
\text { arrivait avec sa flotte, } \\
\text { l'entrée du port et de la ville } \\
\text { d'Utique. }\end{array}$ & \begin{tabular}{|l|} 
Lorsque Tubéron arrive à \\
Utique avec sa flotte, Varus \\
lui interdit l'accès de la ville \\
et du port.
\end{tabular} & $\begin{array}{l}\text { Quand Tubéron arrive sur } \\
\text { Utique avec sa flotte, Varus } \\
\text { lui bloque l'accès au port et } \\
\text { à la ville. }\end{array}$ \\
\hline II 24,4 & $\begin{array}{l}\text { milium circuitu } \\
\text { pidum peruenit. }\end{array}$ & $\begin{array}{l}\text { Il faut prendre un détour de } \\
6 \text { milles pour arriver à la } \\
\text { ville. }\end{array}$ & $\begin{array}{l}\text { C'est un détour de } 6 \text { milles } \\
\text { qu'il faut faire pour atteindre } \\
\text { la place. }\end{array}$ & $\begin{array}{l}\text { If faut faire un détour de } \\
9 \mathrm{~km} \text { pour rejoindre la ville. }\end{array}$ \\
\hline$\pi, 25,1$ & $\begin{array}{l}\text { Curio castra Vari } \\
\text { conspicit muro oppidoque. }\end{array}$ & $\begin{array}{l}\text { Curion observa le camp de } \\
\text { Varus, placé sous les murs } \\
\text { de la ville. }\end{array}$ & $\begin{array}{l}\text { Curion observe que le camp } \\
\text { de Varus est appuyé au mur } \\
\text { de la place. }\end{array}$ & $\begin{array}{l}\text { Curion observe le camp de } \\
\text { Varus. Il était collé au } \\
\text { rempart de la ville. }\end{array}$ \\
\hline II, 25,1 & 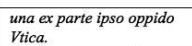 & \begin{tabular}{|l|}
$\begin{array}{l}\text { D'un côté il ítait défendu } \\
\text { par la ville même d'Utique. }\end{array}$ \\
\end{tabular} & $\begin{array}{l}\text { Défendu d'un côté par la } \\
\text { place même d'Utique. }\end{array}$ & \\
\hline II, 25,1 & quod est ante oppidum. & Devant 1 & Qui est & apart de \\
\hline II, 25,3 & $\begin{array}{l}\text { io } D C \\
\text { ex } \\
\text { ue } \operatorname{cCCC} \\
\end{array}$ & $\begin{array}{l}\text { leur seco } \\
\text { numides }\end{array}$ & $\begin{array}{l}600 \text { cava } \\
400 \text { fanta }\end{array}$ & $\begin{array}{l}\text { sortir de la ville } \\
\text { valiers numides et } \\
\text { tassins. }\end{array}$ \\
\hline II 25,5 & $\begin{array}{l}\text { reliqui } \\
\text { oppidu }\end{array}$ & la & fille. & $\begin{array}{l}\text { dans le ca } \\
\text { ville. }\end{array}$ \\
\hline Пп, 26, & ponit. & ville. & & peu de d $^{2}$ \\
\hline III, 26, 4 & $\begin{array}{l}\text { se per litora }[\ldots] \text { celerite } \\
\text { in oppidum recipit. }\end{array}$ & $\begin{array}{l}\begin{array}{l}\text { Elle gagna promptement la } \\
\text { ville en suivant le rivage. }\end{array} \\
\end{array}$ & $\begin{array}{l}\text { Uner } \\
\text { long }\end{array}$ & $\begin{array}{l}\text { en se réfugiant en urgence } \\
\text { dans la ville par le bord de } \\
\text { mer. }\end{array}$ \\
\hline II, 35,3 & $\begin{array}{l}\text { eodem ch } \\
\text { contende }\end{array}$ & $\begin{array}{l}\text { ans } \\
\text { roit à }\end{array}$ & $\begin{array}{l}t \text { leur } \\
\text { sur }\end{array}$ & $\begin{array}{l}\text { Un bon nombre d'entre eux, } \\
\text { dans leur ćlan, filèrent droit } \\
\text { sur la ville. }\end{array}$ \\
\hline II, 35,5 & ese & & & ville, , morts de \\
\hline II, 35,6 & $\begin{array}{l}\text { Qua re animaduersa } \\
\text { Varus et terrore exercitus } \\
\text { cognito bucinatore in } \\
\text { castris et paucis ad } \\
\text { speciem tabernaculis } \\
\text { relictis de tertia uigilia } \\
\text { silentio exercitum in } \\
\text { oppidum reducit. }\end{array}$ & $\begin{array}{l}\text { Varus témoin de ce fait et } \\
\text { de la terreur qui s'était } \\
\text { emparée de son ammée, } \\
\text { laissa dans le camp un } \\
\text { trompette et quelques tentes } \\
\text { pour tromper l'ennemi, ,t } \\
\text { vers la troisière veille il fit } \\
\text { rentrer sans brit ses } \\
\text { troupes dans la place. }\end{array}$ & $\begin{array}{l}\text { Varus s'en aperçoit, et } \\
\text { voyant la démoralisation de } \\
\text { l'armée, il laisse au camp un } \\
\text { trompette et quelques tentes } \\
\text { pour faire illusion, puis, } \\
\text { pendant la troisième veille, } \\
\text { il raméne sans bruit ses } \\
\text { troupes dans la place. }\end{array}$ & $\begin{array}{l}\text { Quand Varus vo } \\
\text { comprend que la } \\
\text { gagne son armée } \\
\text { un trompette au } \\
\text { milieu de quelqu } \\
\text { pour faire illusio } \\
\text { milicu de la nuit, } \\
\text { pointe des pieds, }\end{array}$ \\
\hline II, 36, & $t_{t i} i$ & & & $e$ une \\
\hline II, 38 , & & es dc & & \\
\hline II, 44,2 & & & & $\begin{array}{l}\text { 2, Juba aperçut } \\
\text { e. }\end{array}$ \\
\hline & \begin{tabular}{|l} 
Ipse equo it \\
uectus.
\end{tabular} & $\begin{array}{l}\text { trtré dans } \\
\text { al. }\end{array}$ & $\begin{array}{l}\text { Quant au roi, il fit son entrée } \\
\text { à cheval dans la place. }\end{array}$ & $\begin{array}{l}\text { Juba fit son entrée dans la } \\
\text { ville à cheval. }\end{array}$ \\
\hline
\end{tabular}

34 Utique est qualifiée d'oppidum par César ; elle n'est cependant pas en hauteur, même si une partie de la ville est localisée sur un promontoire dominant un port. Il distingue cependant les deux parties de la ville dans le livre I. Ici, le port, situé dans la zone basse, et la «ville», localisée sur la colline, sont spécifiquement mentionnés alors que César aurait pu n'employer qu'un seul terme. C'est là encore le lien avec une contrainte militaire qui prévaut dans le choix du mot idoine, puisqu'il s'agit de montrer que Varus tient l'intégralité du site, l'interdisant à Tubéron, partisan de César. On peut noter en particulier l'opposition entre le camp, castra, et l'oppidum, la ville, que l'on retrouve très régulièrement dans les descriptions de César mais qui est, pour Utique, particulièrement bien marquée.

Dans notre traduction, nous avons fait le choix de désigner Utique par le terme français de "ville", sauf une fois où nous avons mis son nom pour désigner ses habitants. Le caractère urbain d'Utique à cette date est indéniable, même si c'est une ville encore modeste ${ }^{109}$, il ne peut donc y avoir d'ambiguïté. Le contexte d'emploi renvoie systématiquement aux actions militaires des uns et des autres (évocation des murs, lieu de refuge). La traduction de 1865 opère de la même façon. Pierre Fabre est, lui, partagé entre l'emploi de "ville» et de "place», terme qui relève davantage du rôle stratégique d'Utique et de la présence de la muraille; il met ici en avant un aspect que nous avons choisi de ne pas valoriser afin de ne pas créer de confusion entre le camp voisin et la ville.

Ilerda est le site choisi en Hispanie Citérieure par les Pompéiens pour combattre les Césariens. La valeur stratégique de la région est en effet importante, entre autres pour le ravitaillement des troupes. La ville est sise sur une hauteur et les adversaires ont chacun investi une colline proche pour y installer leur camp. 
Tableau 4. - Ilerda.

\begin{tabular}{|c|c|c|c|c|}
\hline Référence & Texte latin & Nisard & Fabre & Groupe César \\
\hline $\mathrm{I}, 40,4$ & $\begin{array}{l}\text { quem oppido castrisque } \\
\text { coniunctum habebat. }\end{array}$ & $\begin{array}{l}\text { Qu'il avait construit } \\
\text { entre son camp et la } \\
\text { ville. }\end{array}$ & $\begin{array}{l}\text { Qui était tout à côté de la } \\
\text { ville et de son propre } \\
\text { camp. }\end{array}$ & $\begin{array}{l}\text { Qu'il contrôlait à côté } \\
\text { de la ville et du camp. }\end{array}$ \\
\hline $\mathrm{I}, 43,1$ & $\begin{array}{l}\text { Erat inter oppidum } \\
\text { Ilerdam et proximam } \\
\text { collem. }\end{array}$ & $\begin{array}{l}\text { Il y avait entre la place } \\
\text { d'Ilerda et la colline } \\
\text { voisine. }\end{array}$ & $\begin{array}{l}\text { Il y avait entre la place } \\
\text { d'Ilerda et la colline } \\
\text { voisine. }\end{array}$ & $\begin{array}{l}\text { Entre Ilerda et la colline } \\
\text { voisine }[\ldots] \text { il y avait... }\end{array}$ \\
\hline $\mathrm{I}, 43,2$ & $\begin{array}{l}\text { ab oppido et ponte et } \\
\text { commeatu omni quem in } \\
\text { oppidum contulerant se } \\
\text { interclusurum } \\
\text { aduersarios confidebat. }\end{array}$ & $\begin{array}{l}\text { Il ne doutait pas qu'il } \\
\text { n'ôtât aux ennemis toute } \\
\text { communication avec le } \\
\text { pont et la ville d'où ils } \\
\text { tiraient leurs } \\
\text { subsistances. }\end{array}$ & $\begin{array}{l}\text { Il pourrait couper les } \\
\text { ennemis de la ville, du } \\
\text { pont et de tous les } \\
\text { approvisionnements } \\
\text { qu'ils avaient rassemblés } \\
\text { à Ilerda. }\end{array}$ & $\begin{array}{l}\text { il pourrait couper } \\
\text { l'accès de ses } \\
\text { adversaires à la ville, au } \\
\text { pont et au ravitaillement } \\
\text { qu'ils avaient stocké à } \\
\text { llerda. }\end{array}$ \\
\hline I, 45, 1 & $\begin{array}{l}\text { ad oppidum Ilerdam } \\
\text { recipere et sub muro } \\
\text { consistere cogit. }\end{array}$ & $\begin{array}{l}\text { le force à se retirer vers } \\
\text { llerda, jusque sous les } \\
\text { murs de la ville. }\end{array}$ & $\begin{array}{l}\text { l'oblige }[\ldots] \text { à se replier } \\
\text { sur Ilerda et ne s'arrêter } \\
\text { qu'au pied des remparts. }\end{array}$ & $\begin{array}{l}\text { les contraint }[\ldots] \text { à se } \\
\text { replier vers Ilerda et à } \\
\text { ne s'arrêter qu'aux } \\
\text { pieds du rempart. }\end{array}$ \\
\hline $\mathrm{I}, 45,2$ & $\begin{array}{l}\text { sub montem in quo erat } \\
\text { oppidum positum Ilerda } \\
\text { succedunt. }\end{array}$ & $\begin{array}{l}\text { Au pied de la hauteur où } \\
\text { était bâtie la place } \\
\text { d'Ilerda. }\end{array}$ & $\begin{array}{l}\text { Au pied de la hauteur où } \\
\text { était bâtie la place } \\
\text { d'Ilerda. }\end{array}$ & $\begin{array}{l}\text { les voilà au pied de la } \\
\text { colline d'Ilerda! }\end{array}$ \\
\hline $\mathrm{I}, 45,5$ & $\begin{array}{l}\text { Ab oppido autem } \\
\text { decliuis locus tenui } \\
\text { fastigio uergebat in } \\
\text { longitudinem passus } \\
\text { circiter CCCC. }\end{array}$ & $\begin{array}{l}\text { Du côté de la ville, le } \\
\text { terrain s'abaissait en } \\
\text { pente douce dans une } \\
\text { étendue d'environ } \\
500 \text { pas. }\end{array}$ & $\begin{array}{l}\text { A partir de la ville, le } \\
\text { terrain s'abaissait en } \\
\text { faible pente sur un espace } \\
\text { d'environ } 400 \text { pas. }\end{array}$ & $\begin{array}{l}\text { Depuis la ville, le } \\
\text { terrain descendait en } \\
\text { pente douce sur environ } \\
600 \mathrm{~m} \text { de long. }\end{array}$ \\
\hline $\mathrm{I}, 45,7$ & $\begin{array}{l}\text { atque ex castris cohortes } \\
\text { per oppidum crebro } \\
\text { submittebantur. }\end{array}$ & $\begin{array}{l}\text { Des cohortes fraîches } \\
\text { traversaient la ville. }\end{array}$ & $\begin{array}{l}\text { Et du camp, on envoyait } \\
\text { sans cesse, en les faisant } \\
\text { passer par la ville des } \\
\text { cohortes. }\end{array}$ & $\begin{array}{l}\text { Depuis leur camp, des } \\
\text { cohortes arrivaient sans } \\
\text { relâche, en passant par } \\
\text { la ville. }\end{array}$ \\
\hline I, 46, 2 & $\begin{array}{l}\text { Submotis sub murum } \\
\text { cohortibus ac nonnulla } \\
\text { parte propter terrorem } \\
\text { in oppidum conpulsis. }\end{array}$ & $\begin{array}{l}\text { Repoussés sous les murs } \\
\text { et même, en plus d'un } \\
\text { endroit, chassés par la } \\
\text { peur jusque dans la } \\
\text { ville. }\end{array}$ & $\begin{array}{l}\text { Les ennemis sont } \\
\text { repoussés sous les } \\
\text { remparts, et une partie } \\
\text { même rejetée, par suite } \\
\text { d'une panique, jusque } \\
\text { dans la ville. }\end{array}$ & $\begin{array}{l}\text { Voilà que les cohortes } \\
\text { ennemies sont } \\
\text { repoussées sous le } \\
\text { rempart et même, sous } \\
\text { le coup de la panique, } \\
\text { en partie forcées à } \\
\text { rentrer dans la ville. }\end{array}$ \\
\hline I, 47, 3 & $\begin{array}{l}\text { atque in oppidum } \\
\text { compulissent. }\end{array}$ & $\begin{array}{l}\text { L'avait poussé jusque } \\
\text { dans la ville. }\end{array}$ & $\begin{array}{l}\text { L'avait refoulé dans la } \\
\text { ville. }\end{array}$ & $\begin{array}{l}\text { Et à se replier dans la } \\
\text { ville. }\end{array}$ \\
\hline
\end{tabular}

Ilerda la ville est clairement définie en opposition avec le camp d'Afranius, désigné par le terme castra; oppidum exprime donc ici la dimension civile de cette structure urbaine.

Peu d'éléments de description de la ville d'Ilerda figurent dans le texte de César, néanmoins on trouve deux indications utiles qui justifient l'emploi d'oppidum par César : la ville est sur une hauteur, et elle est entourée de murs. Elle ressemble donc à ce que César a pu voir en Gaule, à Bibracte ou à Vesontio. Il ne faut pas oublier que le nord de la péninsule Ibérique a été celtisé, ce qui a donné la civilisation des " castros ${ }^{110}$. Mais ce n'est sans doute pas cet élément qui justifie l'emploi par César du terme oppidum. L'utilisation est semblable à celle des autres dossiers issus du Bellum ciuile : oppidum est employé pour caractériser le cadre militaire des descriptions. Pour la plupart des passages, les trois traductions utilisent "ville». On peut noter qu'à plusieurs reprises, pour faciliter la compréhension du texte, c'est le nom d'Ilerda qui a été repris.

39 J'ai également retenu l'exemple de Gadès, port situé au niveau du détroit de Gibraltar ${ }^{111}$, dans une zone où les îles étaient à l'époque nombreuses. César connaît Gadès : il a été en poste deux fois dans la province d'Ultérieure; il y est venu une première fois en 69-68 av. J.-C., comme questeur ${ }^{112}$, et a eu l'opportunité de rencontrer les notables des diverses cités constituant la province, se rendant dans cette cité ${ }^{113}$ représentée par L. Cornelius Balbus. Elle est en principe protégée par un traité qui garantit son autonomie $^{114}$. César lui a accordé des bienfaits, postérieurement à Pompée, présent en Hispanie lors du conflit contre Sertorius.

40 Là encore, le terme oppidum est employé pour désigner la ville et ce ne sont pas le statut de la ville et son rôle religieux - il y a là le très riche sanctuaire d'Hercule gaditain qui sont évoqués par le terme oppidum, mais bien une dimension militaire. 
Tableau 5. - Gadès.

\begin{tabular}{l|l|l|l|l} 
Référence & Texte latin & Nisard & Fabre & Groupe César \\
\hline II, 18,2 & $\begin{array}{l}\text { Pecuniam omnem } \\
\text { omniaque ornamenta } \\
\text { ex fano Herculis in } \\
\text { oppidum Gadis } \\
\text { contulit. }\end{array}$ & $\begin{array}{l}\text { Il transporta à Gadès } \\
\text { tout l'argent et tous les } \\
\text { ornements qui se } \\
\text { trouvaient dans le } \\
\text { temple d'Hercule. }\end{array}$ & $\begin{array}{l}\text { Tout l'argent et tous les } \\
\text { objets précieux du } \\
\text { temple d'Hercule, il les } \\
\text { fit transporter dans la } \\
\text { place de Gadès. }\end{array}$ & $\begin{array}{l}\text { Il fit transporter tout } \\
\text { l'abjets précieux du } \\
\text { temple d'Hercule dans } \\
\text { la ville de Gadès. }\end{array}$ \\
\hline II, 18,2 & $\begin{array}{l}\text { oppido Gadibus } \\
\text { praefecit. }\end{array}$ & $\begin{array}{l}\text { Et en donna le } \\
\text { commandement à } \\
\text { C. Gallonius. }\end{array}$ & $\begin{array}{l}{[\text { Il] nomma au }} \\
\text { commandement de la } \\
\text { place. }\end{array}$ & $\begin{array}{l}\text { Et mit à la tête des } \\
\text { Gaditains. }\end{array}$ \\
\hline II, 20,2 & $\begin{array}{l}\text { ut Gallonium ex } \\
\text { oppido expellerent. }\end{array}$ & $\begin{array}{l}\text { Pour chasser Gallonius } \\
\text { et conserver à César } \\
\text { l'île et la place. }\end{array}$ & $\begin{array}{l}\text { Chasser Gallonius de la } \\
\text { place. }\end{array}$ & $\begin{array}{l}\text { Pour chasser Gallonius } \\
\text { et garder la ville. }\end{array}$
\end{tabular}

41 On peut d'ailleurs noter que César utilise d'autres termes lorsqu'il souhaite préciser la topographie de Gadès : il mentionne les deux parties ${ }^{115}$, la ville (urbs) et l'île (insula) où se trouve le sanctuaire. Nous sommes là dans un autre contexte, qui ne ressort plus du domaine militaire ${ }^{116}$. Oppidum n'est ici encore utilisé que dans le cadre d'une description d'activités militaires.

42 En Illyrie, Oricum constitue également un exemple intéressant. Il s'agit d'une ville côtière remontant au $v^{e}$ siècle av. J.-C.: son caractère urbain est donc indéniable. Elle était érigée sur un promontoire bien défendu ${ }^{117}$ et sa position en faisait un site stratégique de première importance pour le contrôle des relations avec la péninsule italienne.

Tableau 6. - Oricum.

\begin{tabular}{|c|c|c|c|c|}
\hline Référence & Texte latin & Nisard & Fabre & Groupe César \\
\hline III, 11,3 & $\begin{array}{l}\text { qui iussu Pompei } \\
\text { oppiso praeerat } \\
\text { praesidiumque ibi } \\
\text { Parthinorum habebat, } \\
\text { conatus portis clausis } \\
\text { oppidum defendere. }\end{array}$ & $\begin{array}{l}\text { Qui y commandait pour } \\
\text { Pompée avec une } \\
\text { garnison de Parthini, en } \\
\text { avait fermé les portes, } \\
\text { décidé à se défendre. }\end{array}$ & $\begin{array}{l}\text { Qui commandait la place } \\
\text { par ordre de Pompée, et y } \\
\text { avait sous ses ordres une } \\
\text { garnison de Parthini, fit } \\
\text { fermer les portes et tenta } \\
\text { de défendre la ville. }\end{array}$ & $\begin{array}{l}\text { qui commandait la place } \\
\text { sur ordre de Pompée, et } \\
\text { disposait d'une garnison de } \\
\text { Parthiniens, fit fermer les } \\
\text { portes et essaya d'abord de } \\
\text { défendre la ville. }\end{array}$ \\
\hline III, 11,4 & $\begin{array}{l}\text { oppidani autem etiam } \\
\text { sua sponte Caesarem } \\
\text { recipere conarentur. }\end{array}$ & $\begin{array}{l}\text { Les habitants de leur } \\
\text { côté, voulaient recevoir } \\
\text { César. }\end{array}$ & $\begin{array}{l}\text { Cependant que les } \\
\text { habitants essayaient } \\
\text { spontanément de recevoir } \\
\text { César. }\end{array}$ & $\begin{array}{l}\text { Les habitants, de leur } \\
\text { propre chef, essayaient } \\
\text { d'accueillir César. }\end{array}$ \\
\hline III, 11,4 & $\begin{array}{l}\text { et se atque oppidum } \\
\text { Caesari dedidit. }\end{array}$ & $\begin{array}{l}\text { [II] ouvrit les portes de la } \\
\text { place et se rendit avec } \\
\text { elle à César. }\end{array}$ & $\begin{array}{l}\text { Et livra la ville et lui- } \\
\text { même aux mains de César. }\end{array}$ & $\begin{array}{l}\text { Et se rendit à César, en lui } \\
\text { livrant la ville. }\end{array}$ \\
\hline III, 15,6 & $\begin{array}{l}\text { quorum alter oppidi } \\
\text { muris, alter praesidiis } \\
\text { terrestribus praeerat. }\end{array}$ & $\begin{array}{l}\text { Dont l'un commandait } \\
\text { dans la ville, et l'autre } \\
\text { sur la côte. }\end{array}$ & $\begin{array}{l}\text { Dont l'un commandait la } \\
\text { défense de la place } \\
\text { [d'Oricum], et l'autre les } \\
\text { troupes de rase campagne. }\end{array}$ & $\begin{array}{l}\text { [Ils] commandaient l'un la } \\
\text { défense de la ville, l'autre } \\
\text { les garnisons du côté de la } \\
\text { terre. }\end{array}$ \\
\hline III, 39,1 & $\begin{array}{l}\text { III cohortes Orici oppidi } \\
\text { tuendi causa reliquit. }\end{array}$ & $\begin{array}{l}\text { Ne laissa que trois } \\
\text { cohortes à Oricum, }[\ldots] \\
\text { pour la garde de la ville. }\end{array}$ & $\begin{array}{l}\text { [il] laissa trois cohortes à } \\
\text { Oricum pour défendre la } \\
\text { place. }\end{array}$ & $\begin{array}{l}\text { [il] laissa à Oricum trois } \\
\text { cohortes pour défendre la } \\
\text { ville. }\end{array}$ \\
\hline III, 39,1 & $\begin{array}{l}\text { Huic officio oppidoque } \\
\text { Caninus legatus } \\
\text { praeerat. }\end{array}$ & $\begin{array}{l}\text { Il avait confié ce double } \\
\text { soin à Caninius, son } \\
\text { lieutenant. }\end{array}$ & $\begin{array}{l}\text { A cette fonction et au } \\
\text { commandement de la } \\
\text { place il avait préposé son } \\
\text { légat Caninus. }\end{array}$ & $\begin{array}{l}\text { C'était le légat Caninus qui } \\
\text { était en charge de cette tâche } \\
\text { et de ce lieu. }\end{array}$ \\
\hline III, 39, 2 & $\begin{array}{l}\text { Is naues nostras } \\
\text { interiorem in portum } \\
\text { post oppidum reduxit. }\end{array}$ & $\begin{array}{l}\text { Celui-ci retira les galères } \\
\text { dans le fond du port } \\
\text { derrière la ville. }\end{array}$ & $\begin{array}{l}\text { Ce dernier fit retirer nos } \\
\text { vaisseaux dans le port } \\
\text { intérieur, derrière la ville. }\end{array}$ & $\begin{array}{l}\text { Il fit placer nos bateaux en } \\
\text { retrait dans le port intérieur, } \\
\text { derrière la ville. }\end{array}$ \\
\hline III, 40,1 & $\begin{array}{l}\text { ut ex superiori pugnans } \\
\text { loco integrosque } \\
\text { semper defatigatis } \\
\text { summittens et reliquis } \\
\text { partibus simul ex terra } \\
\text { scalis et classe moenia } \\
\text { oppidi temptans. }\end{array}$ & $\begin{array}{l}\text { De la sorte il combattait } \\
\text { d'un endroit élevé, } \\
\text { envoyait sans cesse des } \\
\text { troupes fraî́hes pour } \\
\text { relever celles qui étaient } \\
\text { fatiguées, et attaquaient à } \\
\text { la fois la ville par terre } \\
\text { avec des échelles. }\end{array}$ & $\begin{array}{l}\text { Combattant ainsi d'une } \\
\text { position plus élevée, il } \\
\text { remplaçait sans cesse par } \\
\text { des troupes fraîches ses } \\
\text { soldats fatigués, et tentant } \\
\text { sur les autres points } \\
\text { l'attaque des murailles de } \\
\text { la place. }\end{array}$ & $\begin{array}{l}\text { Il remplaçait sans relâche } \\
\text { par des troupes fraîches les } \\
\text { soldats fatigués et s'en } \\
\text { prenait aux murailles de la } \\
\text { ville. }\end{array}$ \\
\hline III, 40, 2 & $\begin{array}{l}\text { molem tenuit naturalem } \\
\text { obiectam quae paene } \\
\text { insulam oppidum } \\
\text { effecerat. }\end{array}$ & $\begin{array}{l}\text { Il se saisit d'une hauteur } \\
\text { naturelle qui s'élevait de } \\
\text { l'autre côté de la ville, } \\
\text { où elle formait une } \\
\text { espèce d'île. }\end{array}$ & $\begin{array}{l}\text { Il occupa à l'autre } \\
\text { extrémité la digue } \\
\text { naturelle qui protège le } \\
\text { port et fait d'Oricum une } \\
\text { presqu'île. }\end{array}$ & $\begin{array}{l}\text { Il occupa de l'autre côté la } \\
\text { digue naturelle qui protège } \\
\text { le port et fait de la ville une } \\
\text { presqu'île. }\end{array}$ \\
\hline III, 40,4 & $\begin{array}{l}\text { qui commeatus Byllide } \\
\text { atque Amantia } \\
\text { importari in oppidum } \\
\text { prohiberet. }\end{array}$ & $\begin{array}{l}\text { [Il] le chargea } \\
\text { d'empêcher que les } \\
\text { convois venant de Byllis } \\
\text { et d'Amantia } \\
\text { n'entrassent dans la ville. }\end{array}$ & $\begin{array}{l}\text { Et le chargea d'empêcher } \\
\text { l'entrée dans la place des } \\
\text { convois venant de Byllis et } \\
\text { d'Amantia. }\end{array}$ & $\begin{array}{l}\text { Pour empêcher qu'arrive } \\
\text { dans la ville le ravitaillement } \\
\text { en provenance de Byllis et } \\
\text { Amantia. }\end{array}$ \\
\hline
\end{tabular}

43 Là encore, l'utilisation d'oppidum par César pour évoquer Oricum est toujours lié à un contexte militaire: la mention du commandement de L. Torquatus, sa reddition, l'organisation de la défense par César qui y laisse trois cohortes, les problèmes de 
ravitaillement des troupes. Nous avons à nouveau fait le choix de traduire oppidum par « ville ». Pierre Fabre de son côté a traduit aussi bien par « place » que par « ville».

La dernière ville de l'Empire romain pour laquelle César emploie le terme oppidum à plusieurs reprises est Gomphi en Thessalie.

Tableau 7. - Gomphi.

\begin{tabular}{|c|c|c|c|c|}
\hline Référence & Texte latin & Nisard & Fabre & Groupe César \\
\hline III, 80,1 & $\begin{array}{l}\text { quod est oppidum } \\
\text { primum Thessaliae } \\
\text { uenientibus ab Epiro. }\end{array}$ & $\begin{array}{l}\text { Première ville de Thessalie } \\
\text { en venant d'Épire. }\end{array}$ & $\begin{array}{l}\text { La première ville de } \\
\text { Thessalie quand on arrive } \\
\text { d'Épire. }\end{array}$ & $\begin{array}{l}\text { La première ville de } \\
\text { Thessalie quand on vient } \\
\text { d'Épire. }\end{array}$ \\
\hline III, 80,3 & $\begin{array}{l}\text { omnem ex agris } \\
\text { multitudinem seruorum } \\
\text { ac liberorum in oppidum } \\
\text { cogit. }\end{array}$ & $\begin{array}{l}\text { [II] fit rentrer dans la ville } \\
\text { tout ce qu'il y avait à la } \\
\text { campagne d'hommes libres } \\
\text { et d'esclaves. }\end{array}$ & $\begin{array}{l}\text { [II] fait rentrer dans la ville } \\
\text { toute la foule des esclaves } \\
\text { et des hommes libres qui } \\
\text { étaient aux champs. }\end{array}$ & $\begin{array}{l}\text { Il rassemble dans la ville } \\
\text { toute une foule d'esclaves } \\
\text { et d'hommes libres } \\
\text { ramenée des champs. }\end{array}$ \\
\hline III, 80,3 & $\begin{array}{l}\text { se confidere munitionibus } \\
\text { oppidi. }\end{array}$ & $\begin{array}{l}\text { Il leur mandait que la place } \\
\text { tiendrait. }\end{array}$ & $\begin{array}{l}\text { Il a confiance dans les } \\
\text { fortifications de la place. }\end{array}$ & $\begin{array}{l}\text { Il avait confiance dans les } \\
\text { fortifications de la ville. }\end{array}$ \\
\hline III, 80,6 & $\begin{array}{l}\text { docuit quantum usum } \\
\text { haberet ad subleuandam } \\
\text { omnium rerum inopiam } \\
\text { potiri oppido pleno atque } \\
\text { opulento. }\end{array}$ & $\begin{array}{l}\text { Il leur représenta } \\
\text { l'avantage qu'il y aurait à } \\
\text { prendre une ville riche et } \\
\text { pleine de vivres. }\end{array}$ & $\begin{array}{l}\text { Quelle utilité il y aurait à } \\
\text { s'emparer d'une place } \\
\text { riche et remplie de vivres. }\end{array}$ & $\begin{array}{l}\text { Ils avaient tout intérêt à } \\
\text { s'emparer d'une ville riche } \\
\text { et bien approvisionnée. }\end{array}$ \\
\hline III, 80,7 & $\begin{array}{l}\text { quo uenerat die post } \\
\text { horam nonam oppidum } \\
\text { altissimis moenibus } \\
\text { oppugnare. }\end{array}$ & $\begin{array}{l}\text { Le jour même de son } \\
\text { arrivée, après la neuvième } \\
\text { heure, il commença } \\
\text { l'attaque de cette ville dont } \\
\text { les murailles étaient fort } \\
\text { élevées. }\end{array}$ & $\begin{array}{l}\text { Le jour même de son } \\
\text { arrivée, après la } 9^{e} \text { heure, il } \\
\text { commença l'attaque de la } \\
\text { place malgré la grande } \\
\text { élévation de ses remparts. }\end{array}$ & $\begin{array}{l}\text { Le jour même de leur } \\
\text { arrivée, il lança dans } \\
\text { l'après-midi l'attaque } \\
\text { contre la ville malgré la } \\
\text { hauteur de ses remparts. }\end{array}$ \\
\hline III, 80,7 & $\begin{array}{l}\text { statimque ab oppido } \\
\text { castra mouit et } \\
\text { Metropolim uenit }\end{array}$ & $\begin{array}{l}\text { Il en partit aussitôt, et } \\
\text { arriva à Métropolis. }\end{array}$ & $\begin{array}{l}\text { Puis aussitôt après, leva le } \\
\text { camp et gagna Métropolis. }\end{array}$ & $\begin{array}{l}\text { puis il leva le camp sans } \\
\text { tarder et arriva à } \\
\text { Metropolis. }\end{array}$ \\
\hline III, 80,7 & $\begin{array}{l}\text { sic ut nuntios expugnati } \\
\text { oppidi famamque } \\
\text { antecederet. }\end{array}$ & $\begin{array}{l}\text { Avant les courriers qui } \\
\text { portaient la nouvelle de sa } \\
\text { victoire. }\end{array}$ & $\begin{array}{l}\text { Si rapidement qu'il arriva } \\
\text { avant que la nouvelle ou } \\
\text { quelque bruit de la prise de } \\
\text { Gomphi y soit parvenu. }\end{array}$ & $\begin{array}{l}\text { Plus rapide que les } \\
\text { messagers qui annonçaient } \\
\text { la prise de la ville, plus } \\
\text { rapide même que la } \\
\text { rumeur. }\end{array}$ \\
\hline
\end{tabular}

La localisation de Gomphi lui permet de contrôler deux passages vers la plaine thessalienne; la ville était entourée d'une enceinte de bonne taille dont les portes sont mentionnées ${ }^{118}$. Nous retrouvons à nouveau cette dimension militaire, justifiant l'emploi d'oppidum par César: Androsthénès tente de constituer une garnison pour résister au général. Cette attitude vaut à la "ville", traduction que nous avons privilégiée, d'être pillée, ce qui est le lot commun des villes prises.

Le dernier dossier que j'évoquerai peut surprendre: Alexandrie n'est pas sise dans l'Empire romain à cette date, elle est fort loin du monde celtique, et sa topographie, celle d'un port, n'est pas celle que l'on imagine pour un oppidum. Pourtant, ce terme est employé à plusieurs reprises pour évoquer la capitale du royaume lagide : 
Tableau 8. - Alexandrie.

\begin{tabular}{|c|c|c|c|c|}
\hline Référence & Texte latin & Nisard & Fabre & Groupe César \\
\hline III, 106, 4 & $\begin{array}{l}\text { quos rex in oppido } \\
\text { praesidii causa } \\
\text { reliquerat. }\end{array}$ & $\begin{array}{l}\text { Que le roi avait laissés } \\
\text { en garnison dans cette } \\
\text { ville. }\end{array}$ & $\begin{array}{l}\text { Que le roi avait laissés } \\
\text { en garnison dans la } \\
\text { place. }\end{array}$ & $\begin{array}{l}\text { Que le roi avait laissés } \\
\text { en garnison dans la } \\
\text { ville. }\end{array}$ \\
\hline III, 109, 2 & $\begin{array}{l}\text { Caesaris copiae } \\
\text { nequaquam erant } \\
\text { tantae, ut eis, extra } \\
\text { oppidum si esset } \\
\text { dimicandum, confideret. }\end{array}$ & $\begin{array}{l}\text { César n'avait pas assez } \\
\text { de troupes pour risquer } \\
\text { une bataille hors les } \\
\text { murs. }\end{array}$ & $\begin{array}{l}\text { Les troupes de César } \\
\text { n'étaient pas encore du } \\
\text { tout assez nombreuses } \\
\text { pour qu'il pût compter } \\
\text { sur elles s'il avait fallu } \\
\text { livrer bataille en rase } \\
\text { campagne. }\end{array}$ & $\begin{array}{l}\text { Les troupes de César, } \\
\text { elles, n'étaient pas du } \\
\text { tout assez nombreuses } \\
\text { pour qu'il puisse } \\
\text { compter dessus s'il } \\
\text { devait se battre à } \\
\text { l'extérieur de la ville. }\end{array}$ \\
\hline III, 109, 2 & $\begin{array}{l}\text { Relinquebatur ut se suis } \\
\text { locis oppido teneret. }\end{array}$ & $\begin{array}{l}\text { Il ne lui restait d'autre } \\
\text { parti que de garder le } \\
\text { poste qu'il occupait dans } \\
\text { la ville. }\end{array}$ & $\begin{array}{l}\text { Il ne lui restait qu'un } \\
\text { parti à prendre, c'était de } \\
\text { garder les positions qu'il } \\
\text { occupait dans la place. }\end{array}$ & $\begin{array}{l}\text { Il ne lui restait qu'une } \\
\text { chose à faire : tenir ses } \\
\text { positions dans la ville. }\end{array}$ \\
\hline III, 111, 1 & $\begin{array}{l}\text { occupabat Alexandriam } \\
\text { praeter eam oppidi } \\
\text { partem quam Caesar } \\
\text { cum militibus tenebat. }\end{array}$ & $\begin{array}{l}\text { [Il] s'empara de la ville, } \\
\text { à l'exception du quartier } \\
\text { que celui-ci occupait. }\end{array}$ & $\begin{array}{l}\text { [II] occupait Alexandrie, } \\
\text { sauf le quartier que } \\
\text { tenaient César et ses } \\
\text { soldats. }\end{array}$ & $\begin{array}{l}\text { Il occupait Alexandrie, } \\
\text { à l'exception du quartier } \\
\text { que César tenait avec } \\
\text { ses hommes. }\end{array}$ \\
\hline III, 112, 2 & $\begin{array}{l}\text { angusto itinere et ponte } \\
\text { cum oppido } \\
\text { coniungitur. }\end{array}$ & $\begin{array}{l}\text { [Ils] unissent par un } \\
\text { canal étroit et un pont, le } \\
\text { Phare à la ville. }\end{array}$ & $\begin{array}{l}\text { Un chemin étroit et un } \\
\text { pont, l'unissant ainsi à la } \\
\text { place. }\end{array}$ & $\begin{array}{l}\text { Elle est reliée à la ville } \\
\text { par un passage étroit et } \\
\text { un pont. }\end{array}$ \\
\hline III, 112,3 & $\begin{array}{l}\text { In hac sunt insula } \\
\text { domicilia Aegyptiorum } \\
\text { et uicus oppidi } \\
\text { magnitudine. }\end{array}$ & $\begin{array}{l}\text { Il y a dans cette île des } \\
\text { habitations d'Égyptiens } \\
\text { qui forment un bourg de } \\
\text { la grandeur d'une ville. }\end{array}$ & $\begin{array}{l}\text { Dans cette île sont des } \\
\text { maisons particulières } \\
\text { appartenant à des } \\
\text { Égyptiens, et qui forment } \\
\text { une agglomération aussi } \\
\text { importante qu'une ville. }\end{array}$ & $\begin{array}{l}\text { Sur cette île, il y a des } \\
\text { maisons appartenant à } \\
\text { des Égyptiens et un } \\
\text { quartier gros comme un } \\
\text { bourg. }\end{array}$ \\
\hline III, 112, 7 & $\begin{array}{l}\text { Reliquis oppidi } \\
\text { partibus. }\end{array}$ & $\begin{array}{l}\text { Dans les autres quartiers } \\
\text { de la ville. }\end{array}$ & $\begin{array}{l}\text { Dans les autres quartiers } \\
\text { de la ville. }\end{array}$ & $\begin{array}{l}\text { Dans les autres quartiers } \\
\text { de la ville. }\end{array}$ \\
\hline III, 112,8 & $\begin{array}{l}\text { In eo tractu oppidi pars } \\
\text { erat regiae exigua. }\end{array}$ & $\begin{array}{l}\text { Il y avait dans ce quartier } \\
\text { de la ville une petite } \\
\text { portion du palais. }\end{array}$ & $\begin{array}{l}\text { Cette partie de la ville } \\
\text { comprenait une petite } \\
\text { portion du palais royal. }\end{array}$ & $\begin{array}{l}\text { Dans cette portion de la } \\
\text { ville se trouvait un petit } \\
\text { pavillon du palais royal. }\end{array}$ \\
\hline
\end{tabular}

Comme dans les autres dossiers retenus, César utilise oppidum en lien avec le contexte militaire : ce sont les troupes qui cantonnent, qui se battent à proximité du lieu à prendre, l'oppidum. Trois mentions d'oppidum auraient pu être remplacées par urbs ${ }^{119}$ lorsque César évoque la topographie d'Alexandrie, le pont entre la ville et l'île où se trouve le phare, et le quartier ainsi constitué.

Il faut noter qu'Alexandrie étant une très grande ville à l'époque, elle est constituée de plusieurs parties, ce que rend César quand il évoque les partes de l'oppidum. Nous avons choisi de traduire en utilisant le terme " quartier ", très bien adapté pour la capitale du royaume lagide. Pierre Fabre avait déjà retenu cette solution, et on peut noter que contrairement à son habitude, il traduit ici oppidum par « ville », prenant en compte le statut d'Alexandrie de quasi mégapole ${ }^{120}$ et non son rôle militaire. César utilise aussi le terme uicus ${ }^{121}$ qui est sans doute le terme qui correspond le mieux à la traduction par " quartier ». Cette façon de désigner, oppidum et ses quartiers, oppidi partes, est reprise dans le Bellum Alexandrinum ${ }^{122}$ à trente-six reprises.

C'est presque toujours dans un contexte militaire que César évoque les pôles urbanisés. Oppidum est alors le terme qu'il choisit, qu'il met en relation avec garnisons, enceintes, sièges ou présence d'un camp militaire au voisinage. Car l'oppidum n'est pas un lieu strictement militaire : c'est, bien au contraire, le cadre de vie d'une communauté civile qui est souvent évoqué, devant subir les aléas de la guerre ou prenant des décisions. Si l'oppidum évoque pour César, après la guerre des Gaules, des sites particuliers comme Bibracte ou Vesontio, son usage dans le Bellum ciuile témoigne de sa définition plus large : pour César, l'oppidum est un noyau urbain assez conséquent, une ville. Cela a induit les choix de traduction du Groupe César. 


\section{Conclusion}

50 Si le chercheur doit toujours se référer aux sources dans leur langue d'écriture, il est néanmoins parfois nécessaire d'utiliser des traductions, qui permettent au lecteur souhaitant «lire l'histoire» un contact plus immédiat avec le texte. Savoir qui est le traducteur est alors indispensable : le contexte de traduction est à prendre en compte, ainsi que la culture et les connaissances du traducteur. Ce dernier, par les choix qu'il fait, est conduit à apporter des nuances au texte sur lequel il travaille. Même en étant le plus respectueux possible, par le choix des mots, « ville » ou « place forte » par exemple dans le cas d'oppidum, il induit une lecture différente, plus civile ou plus militaire dans le cas qui nous occupe. Il convient de le savoir et d'en tenir compte. Dans le cas d'une traduction, nommer la ville en utilisant des termes techniques, politiques, juridiques, administratifs, militaires conduit à interpréter le texte latin ou grec.

51 Il convient aussi de rester clair pour le lecteur : traduire c'est aussi permettre à ce dernier de comprendre le texte. Il faut donc respecter ce qu'a écrit l'auteur, et le connaître aide aussi à proposer une traduction la plus fidèle possible qui doit aussi tenir compte du public à qui est destiné l'ouvrage ${ }^{123}$. On ne peut proposer une traduction tout à fait similaire à un agrégatif de lettres classiques, à un public curieux mais non latiniste ou historien, ou à un collégien.

« Nommer la ville » n'est donc pas un problème se cantonnant à l'Antiquité, période pour laquelle les termes techniques désignant une communauté varient ${ }^{124}$ dans le temps, c'est aussi une problématique contemporaine.

\section{BIBLIOGRAPHIE}

\section{Sources}

César, La guerre civile. Tome 1 (Livres I et II), trad. P. Fabre, Paris, CUF, 1936.

César, La guerre civile. Tome 2 (Livre III), trad. P. Fabre, Paris, CUF 1936.

Pseudo-César, Guerre d'Alexandrie, trad. J. Andrieu, Paris, CUF, 2002 (1954).

\section{Références}

CABALlOS RUFINO Antonio (éd.), Carmona romana (Actas del II congreso de Historia de Carmona), Carmona, Delegación de Carmona, Excmo. Ayuntamiento de Carmona, 2001.

CABALLOS RUFINO Antonio (éd.), Carmona romana, vol. I et II, Carmona, Delegación de Carmona, Excmo. Ayuntamiento de Carmona, 2012.

BELTRÁN LLORIS Francisco, « Municipium C. R. “oppidum c. R.” y “oppidum latinum” en la NH de Plinio: una revisión del problema desde la perpectiva hispana », dans J. González (éd.), Ciudades privilegiadas en el occidente romano, Séville, Diputacion y universidad de Sevilla, 1999, p. 247-268. 
COGITORE Isabelle, COUDRY Marianne, DE GIORGIO Jean-Pierre, LEFEBVRE Sabine \& WYLER Stéphanie, «Introduction », dans J.-P. DE GIORGIO (éd.) et al., César, Guerres : guerre des Gaules \& guerre civile, Paris, Les Belles Lettres, coll. « Editio Minor », 2020, p. IX-XXXv.

DE GIORGIO Jean-Pierre (éd.), avec COGITORE Isabelle, COUDRY Marianne, LEFEBVRE Sabine \& WYLER Stéphanie, César, Guerres : guerre des Gaules \& guerre civile, Paris, Les Belles Lettres, coll. «Editio Minor », 2020.

DÉCHELETTE Joseph, Manuel d'archéologie préhistorique et celtique, t. IV : Second âge du fer. Époque de La Tène, Paris, Auguste Picard, 1927.

DEHN Wolfgang, « Aperçu sur les oppida d'Allemagne à la fin de l'époque celtique », Celticum, 4, 1962 , p. 329-386.

DELPLACE Christiane, La romanisation du Picenum. L'exemple d'Urbs Salvia, Rome, École française de Rome, coll. « CEFR, 177 », 1993.

FICHTL Stephan, Les peuples gaulois. $I I I^{e}-I^{e r}$ siècles av. J.-C., Paris, Errance, 2004.

FICHTL Stephan, La ville celtique. Les oppida de 150 av. J.-C. à 15 apr. J.-C., édition revue et augmentée, Paris, Errance, 2005 (2000).

FICHTL Stephan, Les premières villes de Gaule. Le temps des oppida, Lacapelle-Marival, Archéologie Nouvelle, 2012.

GAFFIOT Félix, Dictionnaire illustré latin-français, Paris, Hachette, 1934.

GARDES Philippe, «Oppida et "civilisation des oppida” cent ans après Joseph Déchelette : une introduction », Pallas, 105, p. 151-157.

GENTILI Gino Vinicio, Auximum (Osimo). Regio V-Picenum, Rome, Istituto di Studi Romani, coll. «Italia Romana : Municipi e Colonie, série I, vol. XV », 1955.

GOUDINEAU Christian, «Les oppida de l'âge du fer : recherches et découvertes récentes », Dossiers d'Archéologie, Côte d'Azur : passionnantes découvertes de l'âge du fer aux Romains, 57, 1981, p. 14-15.

GUILLAUMET Jean-Paul, « Rapport introductif sur le rôle du rempart dans l'oppidum, structure pré-urbaine ", dans A. Cahen-Delhaye, A. Duval, G. Leman-Delerive \& P. Leman (éd.), Les Celtes en Belgique et dans le nord de la France : les fortifications de l'âge du fer (Actes du $6^{\mathrm{e}}$ colloque de l'Association française d'étude de l'âge du fer, tenu à Bavay et Mons), Villeneuve-d'Ascq, Revue du Nord, 1984, p. 277-278.

KRUTA Venceslas, Les Celtes. Histoire et dictionnaire, des origines à la romanisation et au christianisme, Paris, Laffont, 2000.

LEFEBVRE Sabine, L'administration de l'Empire romain d'Auguste à Dioclétien, Paris, Colin, coll. «Cursus », 2011.

LEFEBVRE Sabine, « Les réunions de notables hispaniques pendant la guerre civile (49-44 av. J.-C.) ", dans S. Lefebvre (éd.), Identités et dynamiques provinciales du II siècle avant notre ère à l'époque julio-claudienne, Dijon, EUD, 2013, p. 29-60.

LEFEBVRE Sabine, PICARD Christophe, CALLEGARIN Laurent \& VALÉRIAN Dominique, À la croisée des mers et des continents. Le détroit de Gibraltar (Antiquité - Moyen Âge), à paraître.

LEWIS Charlton Thomas \& SHORT Charles, A Latin Dictionary, Oxford, Clarendon Press, 1962.

MORET Pierre, « À quoi servaient les remparts des oppida gaulois ? », Pallas, 105, 2017, p. 173-190. 
MORET Pierre, « The Purpose of Gallic Oppida Ramparts: A Reappraisal », dans A. Ballmer, M. Fernández-Götz \& D. P. Mielke (éd.), Understanding Ancient Fortifications between Regionality and Connectivity, Oxford, Oxbow Books, 2018, p. 171-180.

NICOLET Claude, « Fragments pour une géographie urbaine comparée : à propos d'Alexandrie », dans C. Nicolet, R. Ilbert \& J.-C. Depeaule (éd.), Mégapoles méditerranéennes. Géographie urbaine rétrospective (Actes du colloque de Rome, mai 1996), Rome, École française de Rome, coll. «CEFR, $261 », 2000$, p. 245-252.

NISARD Désiré (éd.), Salluste, Jules César, C. Velleius Paterculus et A. Florus : œuvres complètes, Paris, Firmin Didot, 1865.

PEYRE Christian, La Cisalpine gauloise du III au $I^{e r}$ siècle av. J.-C., Paris, Presse de l'ENS, 1979.

PIERREVELCIN Gilles, Les plus grands sites gaulois. Atlas des oppida, Lacapelle-Marival, Archéologie Nouvelle, 2012.

RODRÍGUEZ NEILA Juan Francisco, El municipio romano de Cádiz, Cadix, Instituto de estudios gaditanos, 1980 .

SALAČ Vladimir, «Les oppida et les processus d'urbanisation en Europe centrale », dans Die Frage der Protourbanisation in der Eisenzeit / La question de la proto-urbanisation à l'âge du fer, Bonn, Habelt, 2012, p. 319-345.

TARPIN Michel, « Oppida ui capta, uici incensi... les mots latins de la ville », Latomus, 58, 1999 (2), p. $279-297$.

TARPIN Michel, « Urbs et oppidum : le concept urbain dans l'Antiquité romaine », dans V. Guichard, S. Sievers \& O. H. Urban (éd.), Les processus d'urbanisation à l'âge du fer / Eisenzeitliche Urbanisationsprozesse (Actes du colloque de Bibracte, 8-11 juin 1998), Glux-en-Glenne, Centre archéologique européen du Mont Beuvray, coll. «Bibracte, 4 », 2000, p. 27-30.

TARPIN Michel, Vici et pagi dans l'Occident romain, Rome, École française de Rome, coll. « CEFR, $299 », 2002$.

$T L L=$ Thesaurus linguae latinae, en ligne sur <www.thesaurus.badw.de/en/about-the-tll/ history.html>.

\section{NOTES}

1. De Giorgio (éd.) et al. (2020). Ce collectif est désigné par le terme Groupe César dans cet article. Nous avons choisi de donner toutes les mesures selon nos unités de mesures actuelles, kilomètres, heures, etc.

2. César, La guerre civile, Tome 1 (Livres I et II) et Tome 2 (Livre III), Paris, 1936.

3. Pour plus de détails sur la méthode de travail, voir Cogitore et al. (2020).

4. À de très rares exceptions, comme pour imperator à quatre reprises. Cf. Cogitore et al. (2020, IXxxxv).

5. Il ne s'agit évidemment pas ici de reprendre l'ensemble du dossier, mais de proposer une rapide synthèse destinée à éclairer les choix de traduction.

6. Tarpin (2000).

7. Sur l'origine du mot, voir les propositions de Servius, ad Aeneid, IX, 605 : Quatit oppida bello oppidum quidam a uico castelloque magnitudine secernunt : alii locum muro fossaue aliaue qua munitione conclusum : alii locum aedificiis constitutum, ubi fanum comitium forum et murus sit; alii oppidum ab 
oppositione murorum; uel quod hominibus locus esset oppletus; uel quod opes illo munitionis gratia congestae sunt.

8. Gaffiot (1934).

9. Lewis \& Short (1962).

10. Tarpin $(2000,28)$.

11. Ibid.

12. Thesaurus Linguae Latinae (TLL), IX-2, p. 754-759 (1976) ; parmi les sens du mot, on peut noter, col. 754 : sedes ciuitatis, urbs, entre autres, chez Pline l'Ancien, Histoire naturelle, III, 7.

13. Cicéron, De Republica, I, 41 : quam cum locis manuque saepsissent, eius modi coniunctionem tectorum oppidum uel urbem appellauerunt, delubris distinctam spatiisque communibus.

14. Varron, De Lingua Latina, V, 143 : Oppida condebant in Latio Etrusco ritu, ut multa, id est iunctis bubus, tauro et uacca interiore, aratro circumagebant sulcum. Hoc faciebant religionis causa die auspicato, ut fossa et muro essent muniti. Terram unde exculpserant, fossam uocabant et introrsum iactam murum.

15. Tite-Live, XLII, 36 : Per idem tempus legati ab rege Perseo uenerunt. Eos in oppidum intromitti non placuit, cum iam bellum regi eorum et Macedonibus et senatus decresset et populus iussisset.

16. Tite-Live n'utilise pas le terme de ciuitas quand il parle des Gaulois cisalpins du III $^{\mathrm{e}}$ siècle av. J.-C., dont il juge sans doute les institutions comme étant trop "embryonnaires »; cf. Peyre (1979, 56 ; pour les oppida, 59-62).

17. Tite-Live, XXII, 11 : Edictoque proposito ut, quibus oppida castellaque immunita essent, ut ii commigrarent in loca tuta.

18. Voir, par exemple, Beltrán Lloris (1999).

19. Peyre $(1979,59)$.

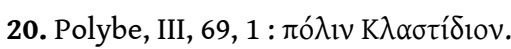

21. Tite-Live, XXI, 48, 9 : ad Clastidium uicum.

22. Tite-Live, XXXII, 29, 7 : Oppida Clastidium et Litubium, utraque Ligurum. Clastidium contrôlait le défilé de Stadella, stratégique, car il ouvrait sur l'Émilie.

23. César, Bellum Gallicum, V, 21, 3-4: Oppidum autem Britanni uocant, cum siluas impeditas uallo, atque fossa munierunt, quo incursionis hostium uitandae causa conuenire consuerunt. 4 : Eo proficiscitur cum legionibus : locum reperit egregie natura atque opere munitum.

24. César, Bellum Gallicum, VII, 68-69 et 84 .

25. César, Bellum Gallicum, I, 38 : Cum tridui uiam processisset, nuntiatum est ei Ariouistum cum suis omnibus copiis ad occupandum Vesontionem, quod est oppidum maximum Sequanorum, contendere, triduique uiam a suis finibus profecisse. Id ne accideret magnopere sibi praecauendum Caesar existimabat. Namque omnium rerum quae ad bellum usui erant summa erat in eo oppido facultas, idque natura loci sic muniebatur ut magnam ad ducendum bellum daret facultatem, propterea quod flumen [alduas] Dubis ut circino circumductum paene totum oppidum cingit; reliquum spatium, quod est non amplius pedum M sexcentorum, qua flumen intermittit, mons continet magna altitudine, ita ut radices montis ex utraque parte ripae fluminis contingant. Hunc murus circumdatus arcem efficit et cum oppido coniungit. Huc Caesar magnis nocturnis diurnisque itineribus contendit occupatoque oppido ibi praesidium conlocat.

26. Fichtl $(2005,11)$.

27. Fichtl $(2005,15)$.

28. Cicéron, 2 Verrines, IV, 72, XXXIII : Segesta est oppidum peruetus in Sicilia.

29. Goudineau (1981, 14-15).

30. Déchelette (1927). Cf. Gardes (2017).

31. Je résume ici les propos de Fichtl (2005, 11-24).

32. César, Bellum Gallicum, I, 6, 3 : Extremum oppidum Allobrogum est proximumque Heluetiorum finibus Genua.

33. Tite-Live, XXII, 11.

34. Fichtl $(2005,13)$; Moret $(2017,173-190)$, qui remet en cause l'évolution historique supposée avoir amené l'apparition des oppida ; Moret (2018). 
35. Fichtl $(2005,12)$.

36. Je renvoie pour une présentation historiographique plus ample à Fichtl $(2005,17-20)$. On peut aussi évoquer le bilan historiographique de Salač (2012), dans lequel l'auteur propose d'envisager aussi bien des oppida de hauteur que des oppida de plaine.

37. Kruta (2000, 762-763).

38. Fichtl (2005).

39. Fichtl (2004).

40. Fichtl (2005, 11-40).

41. Dehn (1962).

42. Guillaumet (1984).

43. Fichtl (2005, 11-16).

44. Fichtl (2005, cartes p. 20 et 22-23 pour l'extension de la civilisation des oppida).

45. Tarpin $(2000,27)$ : «Le même site peut être désigné comme urbs et comme oppidum. Les deux termes sont donc interchangeables. »

46. Fichtl (2005). On peut ajouter plus récemment Fichtl (2012).

47. Aulu-Gelle, Nuits attiques, XVIII, 7, 5 : "ciuitatem" et pro loco et oppido et pro iure quoque omnium et pro hominum multitudine.

48. La traduction de ciuitas dans le Bellum Gallicum a entraîné une discussion au sein du Groupe César.

49. Lefebvre $(2011,154)$.

50. Pour la période préromaine, voir Fichtl $(2012,238)$ : «Plusieurs oppida sont connus pour cette ciuitas. » Dans cet ouvrage, il analyse plusieurs termes (ciuitas, pagus, natio, finis, regio) mais pas oppidum.

51. Fichtl $(2005,16)$

52. Fichtl $(2005,15)$.

53. Il l'est moins quand il évoque l'oppidum des Parthini (BC, III, 41, 1) sous la forme qu'il emploie souvent dans la guerre des Gaules (oppidum + le nom d'un peuple). En effet, il ne mentionne pas de ville relevant de ce peuple qui est toujours mentionné comme un groupe humain : cf. $B C$, III, 11,$3 ; 42$, 4 et 5 ; Tite-Live, XXIX, 12, 3 : Parthinosque et propinquas alias gentes motas esse ad spem nouandi res ; 13 : ut Parthini et Dimallum et Bargullum et Eugenium Romanorum essent ; Suétone, Diuus Augustus, 19: item Asini Epicadi ex gente Parthina ibridae. Le Groupe César a choisi pour ce cas particulier de traduire oppidum par "place forte », la présence d'une ville au sens romain du terme n'étant pas attestée. Il existe néanmoins une ville, Parthus, mentionnée par Étienne de

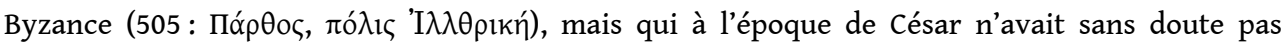
encore une physionomie suffisamment urbaine pour être ainsi considérée, tout comme les deux forteresses d'Eugenium et de Bargulum mentionnées par Tite-Live.

54. On peut noter dans Fichtl (2012) que sont évoquées les régions suivantes: la Gaule méridionale (93-104) ; les castra de la péninsule Ibérique (105-110) ; l'Europe centrale (115-122) et les îles Britanniques (123-130), mais en aucun cas l'Italie, la côte dalmate ou l'Afrique du Nord. De même, ces dernières régions ne figurent pas dans Pierrevelcin (2012).

55. Pour Salone, César évoque le site; cf. BC, III, 9, 2: oppidum oppugnare instituit (est autem oppidum et loci natura et colle munitum). Il s'agit d'une ville côtière.

56. Tarpin $(2000,27)$ : «La richesse du vocabulaire utilisé par les auteurs de langue latine pour désigner tout type d'agglomérations et de communautés qu'ils pouvaient rencontrer montre que l'on distinguait plusieurs catégories. »

57. Ils ont pourtant un rôle, étant souvent le siège du pouvoir local, le centre économique et religieux ; cf. Tarpin $(2000,29)$.

58. BC, III, 11, 1 : atque omnibus oppidis mutatis ad celeritatem iumentis ad Pompeium contendit. 
59. Tarpin $(2000,29)$ : «Pour les érudits du temps, l'oppidum se caractérisait donc par la manifestation de la puissance, à la fois par la capacité de défense et par l'accumulation de richesse."

60. $B C, \mathrm{I}, 12,1$ : oppidum munire.

61. $B C, \mathrm{I}, 12,2$ : diffisus municipii uoluntati. Cela est confirmé en $B C, \mathrm{I}, 12,3$ : confisus municipiorum uoluntatibus. Sur les décisions prises localement, voir aussi $B C, I, 13,1$ avec les décurions d'Auximum.

62. Gentili (1955).

63. BC, I, 12, 3 : Quod oppidum Attius cohortibus introductis tenebat.

64. Sur le Picenum avant les Romains, voir Delplace (1993, 1-3), qui montre bien que la population n'est pas celtique, même si une influence gauloise (sénone) est à noter au IV siècle av. J.-C. ; pour plus de précisions, voir Delplace (1993, 3, note 17).

65. L'enceinte daterait de 174 av. J.-C.

66. Velleius Paterculus, I, 15.

67. $B C, \mathrm{I}, 13,1$ : oppido moenibusque prohiberi.

68. $B C, \mathrm{I}, 13,2$ : ex oppido educi ac profugit.

69. $B C$, III, 29, 1 : quod oppidum iis antea Caesar adtribuerat muniendumque curauerat.

70. $B C$, III, 9,2 et 4 (voir plus bas).

71. $B C, \mathrm{I}, 38$ (voir plus haut).

72. $B C, \mathrm{I}, 15,3$.

73. $B C, \mathrm{I}, 12,3 ; 13,1$ et 2 .

74. Voir plus bas.

75. On y trouve une enceinte : cf. Delplace $(1993,300)$.

76. BC, I, 18, 1 : quod oppidum a Corfinio VII milium intervallo abest [...]; qui id oppidum VII cohortium praesidio tenebant.

77. BC, II, 23, 4 : Id oppidum C. Considius Longus unius legionis praesidio tuebatur.

78. BC, II, 19, 3 : tuendi oppidi causa apud se retinuit; II, 21,1: quod oppidum in sua potestate studuissent habere.

79. BC, III, 5, 1 : Hiemare Dyrrachii, Apolloniae omnibusque oppidis maritimis constituerat.

80. $B C$, III, 9, 8: Iamque hiems adpropinquabat, et tantis detrimentis receptis Octauius desperata oppugnatione oppidi Dyrrachium sese ad Pompeium recipit.

81. $B C, \mathrm{I}, 16,3$ (voir plus bas).

82. BC, III, 9, 4 : Quorum cognita sententia Octauius quinis castris oppidum circumdedit. On trouve la même opposition à Sulmo, cf. BC, I, 18,5: Quorum aduentu altera castra ad alteram oppidi partem ponit.

83. $B C, \mathrm{I}, 18,2$.

84. $B C$, III, 11,4 .

85. $B C, \mathrm{II}, 11,1$ : Quo malo perterriti subito oppidani.

86. BC, I, 61, 5 : Id erat oppidum positum ad Hiberum miliaque passuum a castris aberat XX.

87. $B C$, III, 11, 1 (voir plus haut).

88. Delplace (1993, 35-38).

89. $B C, \mathrm{I}, 15,3$ : Id oppidum Lentulus Spinther X cohortibus tenebat.

90. BC, I, 15, 3 : profugit ex oppido.

91. César encercle ainsi la ville de Sulmo, cf. BC, I, 18, 6 : Reliquis diebus oppidum uallo castellisque circumuenire instituit. On peut aussi évoquer la menace pesant sur Brindes encore tenue par Pompée, cf. BC, I, 27, 3 : [...] ne sub ipsa profectione milites oppidum inrumperent.

92. Otacilius, de Lissus : BC, III, 29, 1 : Otacilius sibi timens <ex> oppido fugit.

93. M. Aurelius Cotta chassé de Caralis, cf. BC, I, 30, 3 : nondum profecto ex Italia sua sponte Cottam ex oppido eiciunt.

94. À Apollonia, cf. BC, III, 12, 3 : Illi ad Caesarem legatos mittunt oppidoque recipiunt. 
95. Voir plus bas.

96. $B C$, III, 21, 5 : quae proditionem oppidi appararet.

97. BC, III, 101, 3 : uix oppidum defenderetur [...] ; 4 : Sed opportunissime nuntiis adlatis oppidum fuit defensum.

98. $B C$, III, 102, 7 : oppido ac portu recepti non erant.

99. BC, I, 15, 2 : quod oppidum Labienus constituerat. Cf. Delplace (1993, 69, note 187) : oppidum serait ici employé par César pour désigner une position géographique et n'a pas ici un contenu politique, comme dans la formule oppidum $c$. R. qui renvoie à un statut antérieur à celui de municipe ; p. 76-77 pour la notice sur Cingulum.

100. Caballos Rufino (2001 et 2012).

101. BC, II, $4:$ Isdem diebus Carmonenses, quae est longe firmissima totius prouinciae ciuitas, deductis tribus in arcem oppidi cohortibus a Varrone praesidio, per se cohortes eiecit portasque praeclusit.

102. Nisard (1865).

103. Fabre (1936 et 1959).

104. Cogitore et al. (2020, XXXI).

105. Delplace $(1993,300)$.

106. BC, II, 1, 3 : Huius quoque spatii pars ea quae ad arcem pertinet loci natura et ualle altissima munita longam et difficilem habet oppugnationem.

107. BC, II, 5, 3 : Facile erat ex castris $C$. Treboni atque omnibus superioribus locis prospicere in urbem.

108. C'est ici la ville qui pourrait être opposée à la campagne, au territoire rural de la cité ; cf. Tarpin $(2000,28)$.

109. Utique est en effet à cette date une ville d'origine phénicienne, fondée vers le $\mathrm{x}^{\mathrm{e}}$ siècle av. J.-C., comme comptoir commercial. Lors de la troisième guerre punique, elle se range aux côtés de Rome, y gagne le statut de cité (ciuitas) libre et immune, et devient la capitale de la nouvelle province. Les fouilles archéologiques, déjà anciennes, ne permettent pas de restituer beaucoup de monuments de la période républicaine.

110. On peut noter que César emploie le terme oppidum pour Octogesa, proche de l'Èbre et du champ de bataille d'Ilerda: BC, I, 61,5: Id erat oppidum positum ad Hiberum miliaque passuum a castris aberat XX. Sa localisation n'est pas encore confirmée par l'archéologie.

111. Lefebvre, Picard, Callegarin \& Valérian (à paraître).

112. Bellum Hispaniense, XLII, 1 ; Velleius Paterculus, II, 43, 4 ; Suétone, César, VII, 1 : Quaestori ulterior Hispania obuenit; Plutarque, Vie de César, V; Dion Cassius, XXXVII, 52, 2. Il est alors le collègue du propréteur $\mathrm{C}$. Antistius Vetus.

113. Suétone, César, VII, 1 : Gadisque uenisset. Cf. Lefebvre (2013, 29-60).

114. Cicéron, Pro Balbo, XV, 34. Cf. Rodríguez Neila (1980).

115. BC, II, 20.

116. Ce que nous avons aussi constaté pour Massalia.

117. Depuis les premières recherches archéologiques menées en 2008 par la Fondation Octopus, une porte dans le mur de fortification a été découverte.

118. $B C$, III, 80,3 .

119. C'est ce qui a été fait pour Massalia, voir ci-dessus.

120. Nicolet (2000).

121. Tarpin (1999 et 2002).

122. Pseudo-César, Guerre d'Alexandrie.

123. Dans le cas de la traduction du Groupe César, les choix ont été fait en fonction du lecteur, cible de notre version des Guerres de César.

124. Leptis Magna fut cité pérégrine, puis municipe latin sous Vespasien, puis colonie romaine sous Trajan. 


\section{RÉSUMÉS}

Il n'est pas ici envisagé de revenir en détail sur le terme oppidum et sur sa définition, mais plutôt de voir comment dans le cadre d'une œuvre, le Bellum ciuile de César, il a été employé. C'est principalement à partir de son emploi dans le Bellum Gallicum que les analyses ont jusque-là porté. Aussi, le contexte d'utilisation par l'auteur, dans une œuvre postérieure à la guerre des Gaules, conduit d'une part à s'interroger sur le choix du terme oppidum par César, et d'autre part à proposer des traductions différentes du mot ; c'est à travers plusieurs exemples que je souhaite évoquer la complexité de la démarche du traducteur.

Our purpose here is not to analyze again in detail the term oppidum and its definition, but rather to see how it was used in the specific context of Caesar's Bellum ciuile. Previous analyses focused mainly on its use in the De Bello Gallico. Thus, the context in which the author uses the term oppidum in a work completed after the Gallic War leads, on the one hand, to question Caesar's choice of the word oppidum, and, on the other hand, to propose different translations for it; it is through several examples that I wish to underline the complexity of the translator's approach.

\section{INDEX}

Mots-clés : César, Bellum ciuile, oppidum, traduction

Keywords : Caesar, Bellum ciuile, oppidum, translation

\section{AUTEUR}

\section{SABINE LEFEBVRE}

Université Bourgogne Franche-Comté, UMR 6298 ARTEHIS

sabine.lefebvre@u-bourgogne.fr 